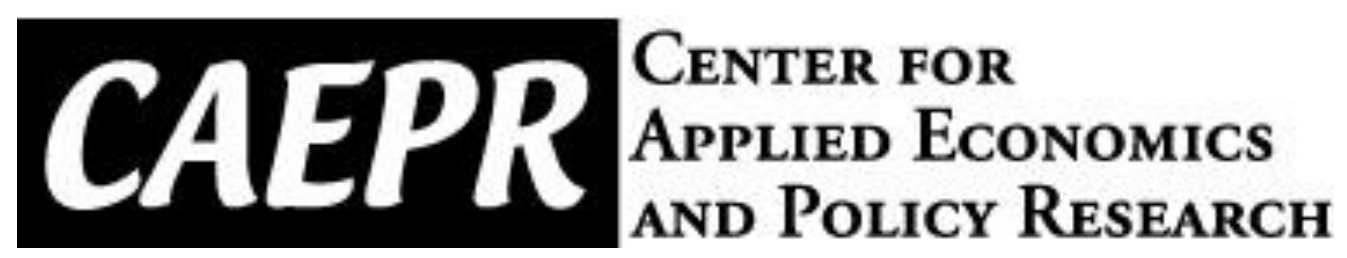

CAEPR Working Paper

\#2012-007

\title{
On Ramsey Equilibrium: Capital Ownership Pattern and Inefficiency
}

\author{
Robert A. Becker \\ Indiana University \\ Ram Sewak Dubey \\ MONTCLAIR State University \\ Tapan Mitra \\ Cornell University
}

November 11, 2012

This paper can be downloaded without charge from the Social Science Research Network electronic library at http://ssrn.com/abstract=2178117

The Center for Applied Economics and Policy Research resides in the Department of Economics at Indiana University Bloomington. CAEPR can be found on the Internet at:

http://www.indiana.edu/ caepr. CAEPR can be reached via email at caepr@indiana.edu or via phone at 812-855-4050.

(C2012 by Robert Becker, Ram Sewak Dubey, Tapan Mitra. All rights reserved. Short sections of text, not to exceed two paragraphs, may be quoted without explicit permission provided that full credit, including $\odot$ notice, is given to the source. 


\title{
On Ramsey Equilibrium: Capital Ownership Pattern and Inefficiency
}

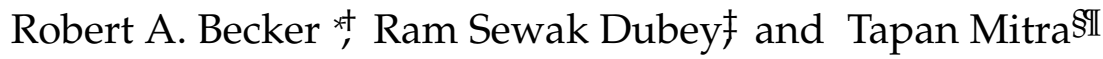

October 27, 2012

\begin{abstract}
We provide a sufficient condition on the production function under which eventually the most patient household owns the entire capital stock in every Ramsey Equilibrium, called the turnpike property. This generalizes the result in the literature which establishes the turnpike property using the capital income monotonicity condition. We then provide an example of a Ramsey Equilibrium in which the most patient household reaches a no capital position infinitely often. This is a strong refutation of the turnpike property on Ramsey equilibria. We also show that the constructed Ramsey equilibrium is inefficient in terms of the aggregate consumption stream that it provides.

Keywords: Cass Criteria, Efficiency, Maximal Income Monotonicity, Period Three Ramsey Equilibrium Cycle, Weak Turnpike Property, Approximate CES Function.

Journal of Economic Literature Classification Numbers: C61, D61, D90, 041.
\end{abstract}

\section{Introduction}

The "folklore result" on Ramsey equilibria is that eventually the most patient household owns the entire capital stock of the economy. The comprehensive survey paper by Becker (2006) points out that this result does not hold in general. In this paper, we revisit the issue of the ownership pattern of capital in the standard dynamic model of Ramsey equilibrium, and relate this with the issue of the possible inefficiency of Ramsey Equilibria.

In the literature on Ramsey equilibria, one says that a turnpike property obtains if every household other than the most patient one eventually reaches a no capital position and maintains that state thereafter. An example by Stern (1998) shows that without additional assumptions on technology and/or preferences, this turnpike property does not obtain. The general result on long-run behavior of Ramsey Equilibria that has been established by Becker and Foias (1987) is the following recurrence theorem: the no capital state is recurrent for every household other than the most patient one. That is, for every household other than the most patient one, it is the case that no capital is owned infinitely often.

\footnotetext{
${ }^{*}$ Corresponding Author

${ }^{\dagger}$ Department of Economics, Indiana University, Bloomington, IN 47405; E-Mail: becker@indiana.edu.

${ }^{\ddagger}$ Department of Economics and Finance, Montclair State University, Montclair, NJ 07043; E-mail: dubeyr@mail.montclair.edu.

§ Department of Economics, Cornell University, Ithaca, NY 14853; E-mail: tm19@cornell.edu.

II We have benefitted from insightful remarks of the seminar participants at the Cornell-Penn State Macroeconomics Conference, Ithaca, September, 2011, the European General Equilibrium Meetings, Exeter, May 2012 and the Midwest Economic Theory Conference, St. Louis, October, 2012.
} 
A weaker property than the turnpike property (which we refer to as the "weak turnpike property") is that eventually the most patient household is never in a no capital position; that is, after at most a finite number of periods, the most patient household always owns some capital stock (although the household need not own the entire capital stock). The literature does not contain any result which says that this weaker turnpike property obtains for all Ramsey equilibria. However, all known examples ${ }^{\boxplus}$ of Ramsey equilibria satisfy this weaker property.

In a recent paper, Becker and Mitra (2012) show that if a Ramsey equilibrium satisfies the weak turnpike property then it satisfies the transversality condition of Malinvaud (1953) and is therefore intertemporally efficient (in terms of the aggregate consumption stream that it provides). This result provides a link between the ownership pattern of capital and the efficiency of Ramsey Equilibria; in particular, the result implies that when the turnpike property on the ownership of capital is satisfied, the Ramsey Equilibria must be efficient, even though the notion of a Ramsey equilibrium involves borrowing constraints, a possible source of inefficiency. Further, this result implies that in all the known examples of Ramsey equilibria in the current literature, Ramsey equilibria are efficient.

Asymptotic properties like the turnpike property and the weak turnpike property place restrictions on the Ramsey equilibrium path itself, and are in general hard to check, given the primitives of the model (specification of production and utility functions, and discount factors of agents). To overcome this problem, the approach taken in the literature has been to note that if the capital stock sequence along a Ramsey equilibrium path converges, then the turnpike property on the ownership pattern of capital holds (a result due to Becker and Foias (1987)). One can then seek restrictions on the primitives of the model under which such a convergence property holds.

The basic result, following this approach, is that if capital income is monotone increasing in the capital stock $(\mathrm{CIM})$, then the capital stock sequence along a Ramsey Equilibrium path must converge (Becker and Foias (1987)). In this paper, we generalize this finding by focusing instead on the maximal income that a single agent can have. This is the capital income when the agent holds the entire capital stock plus the agent's wage income. We show that if this maximal income is monotone increasing in the capital stock ( $(\mathrm{MIM})$, then the capital stock sequence along a Ramsey Equilibrium path must converge. Since an agent's wage income is monotone increasing in the capital stock (given the concavity of the production function), the maximal income of an agent is clearly monotone increasing if CIM holds. But, it can be monotone increasing in the capital stock even when CIM does not hold.

Among commonly used production functions, the capital income monotonicity condition is satisfied by the Cobb-Douglas production function. The maximal income monotonicity condition is satisfied, in addition, by a subclass of production functions with lower elasticity of substitution than the Cobb-Douglas case.

The above account sheds little light on the ownership pattern and efficiency of Ramsey Equilibria when MIM does not hold, or more generally, when the capital stock sequence along a Ramsey equilibrium path fails to converge. However, we do have some partial results in this direction. It is known that period two Ramsey equilibrium cycles can exist (Becker and Foias (1987), Stern (1998)); such cycles clearly violate the capital stock convergence property. Further, all such cycles can be shown to satisfy the weak turnpike property on the ownership pattern of capital, and are therefore efficient (Becker and Mitra (2012)). In particular, this result shows that the weak turnpike property on the ownership pattern of capital and efficiency of Ramsey Equilibria can hold even when MIM is violated.

\footnotetext{
${ }^{1}$ See for example, Becker and Foias (1987), Sorger (1994), Sorger (1995), Stern (1998), Becker (2006) for some useful examples.
} 
Beyond this result, our knowledge of the nature of Ramsey Equilibria is largely incomplete. It seems to us, given the above account, that a basic question that needs to be resolved is whether Ramsey Equilibria always satisfy the weak turnpike property. In this paper we settle this issue by providing an example of a Ramsey Equilibrium in which the most patient household reaches a no capital position infinitely often (in fact, periodically, since our example is of a period three cyclic Ramsey equilibrium), and the Ramsey Equilibrium is inefficient ${ }^{\mathbb{D}}$.

Our approach to constructing the example mentioned above is to first study the necessary conditions for an inefficient Ramsey equilibrium to occur. We expect these necessary conditions to be especially restrictive in the case of inefficient Ramsey equilibrium cycles. This can be helpful as it can pin down both the nature of the program as well as the required restrictions on the primitives (preferences, technology, discount factors) of the model.

In view of the Becker and Mitra (2012) result on period-two Ramsey Equilibrium cycles, we examine the necessary conditions for a period three Ramsey Equilibrium cycle to exist and be inefficient. The choice of period three is dictated by the observation that if an example can be constructed of an inefficient Ramsey equilibrium cycle, then an attempt to show this in the period three case will involve verifying a minimal number of Ramsey-Euler inequalities and feasibility conditions. Furthermore, and for the same reason, we confine ourselves to the case of two households.

The necessary conditions turn out to be clear-cut. The path can be of only one type, attaining a peak capital stock above the golden-rule, followed by a lower capital stock also above the golden rule, followed by a capital stock below the golden-rule. Further, there must be a complete switch of ownership of capital: the patient person must hold the entire capital stock when the capital stock reaches its peak. The less patient person must hold the entire capital stock in the very next period. The period in which the patient person accumulates the capital to its peak level must also be the period in which the patient person consumes the most. Similarly, the period in which the impatient person accumulates capital to go from a no capital position to owning the entire stock of capital must also be the period in which the impatient person consumes the most.

These conditions impose strong restrictions on the production function, but they are not inconsistent with the general assumptions placed on it. In particular, we make the observation that these conditions can be consistent with the standard assumptions on the production function if (a) the golden-rule consumption is sufficiently high compared to the golden-rule capital stock, and (b) the production function exhibits a sharp change as the capital stock crosses the golden rule level, with most of the income consisting of rental income for capital stocks below (and close to) the golden-rule stock, and most of the income consisting of wage income for capital stocks above the golden-rule stock.

There are also restrictions on discount factors that must hold. In particular, with the convention that the first household is the patient one, the discount factors $\delta_{i}$ (for $i=1,2$ ) must satisfy the restriction:

$$
\delta_{2}<\left(\delta_{1}\right)^{4} .
$$

Furthermore, the impatient household's discount factor must be bounded above by a "universal constant"(that is, a number independent of the production and utility functions):

$$
\delta_{2} \leq \sqrt{2}-1 \approx 0.414 .
$$

The example is constructed by choosing a production function for which the pattern of consumption and capital ownership described above will be feasible. The appropriate Ramsey-Euler

\footnotetext{
${ }^{2}$ It is important to note at this stage itself that the significance of period three in the theory of dynamical systems has no bearing on this choice.
} 
equations and inequalities can then be verified by choosing the utility functions and discount factors suitably. The discount factor of the impatient household in the constructed example is considerably smaller than that given by (D) above. The choice of the utility functions and discount factors have to be such that the less patient person finds it interesting to save out of wage income when the capital stock achieves its peak level and exhibits its smallest marginal product.

The inefficiency of the Ramsey Equilibrium occurs because of the fact that the compound (or geometric) returns to capital investment are negative over longer and longer horizons. The negative returns to capital investment takes place because the aggregate capital stock exceeds the golden-rule stock infinitely often (in two of the three periods in each cycle). The implied shadow prices of capital satisfy the well-known Cass criterion (Cass (1972)) for inefficiency.

It is worthwhile to point out that in the example the capital stock depreciates completely in each period. In a recent working paper, Becker et al. (2012) have shown that for a sufficiently low capital depreciation rate, Ramsey Equilibria turn out to be efficient in the more general setting of an economy with elastic labor supply. The role of depreciation rate in establishing efficiency is a topic for further research.

\section{Criteria for Efficiency}

Production takes place using a single capital good. The productive technology turns labor and capital goods into a composite good that can be either consumed or saved as next period's capital input. The amount of labor is fixed in this economy (there will be one unit of labor services per household and all labor services are assumed to be identical). The technology is summarized by a production function, denoted by $f$. Let $y=f(k)$ denote the composite good $y$ produced from a fixed amount of labor (whose value is suppressed in the notation), together with a nonnegative capital input $k$. Capital is assumed to depreciate completely within the period. Hence, the model is formally one with circulating capital that is consumed within the production period. The output $y$ is available for consumption or capital accumulation with a one-period lag. The formal properties of $f$ are recorded as Assumption I.

Assumption $\mathbf{I}: \quad f: \mathbb{R}_{+} \rightarrow \mathbb{R}_{+}, f(0)=0 ; f$ is continuous, increasing and concave on $\mathbb{R}_{+}, f$ is $\mathscr{C}^{(2)}$ on $\mathbb{R}_{++}$, with $f^{\prime}>0$ and $f^{\prime \prime}<0$ on $\mathbb{R}_{++}$, and $\lim _{k \rightarrow 0} f^{\prime}(k)=\infty, \lim _{k \rightarrow \infty} f^{\prime}(k)=0$.

This assumption implies there is a maximum sustainable capital stock, denoted $B$, satisfying $B=f(B)>0$.

The capital stock sequence $\left\{K_{t-1}\right\}, t=1,2 \cdots$ is a capital stock program if $K_{t-1} \geq 0$ and $f\left(K_{t-1}\right)-K_{t} \geq 0$ for each $t \geq 1$. The corresponding consumption program is $\left\{C_{t}\right\}$ with $C_{t}=f\left(K_{t-1}\right)-K_{t}$. The capital stock program and corresponding consumption programs are feasible if $K_{0}=k_{0}>0$, where $k_{0}$ is the given starting stock. Assumption I implies that if the initial aggregate capital stock $k_{0}$ is smaller than $B$, then all nonnegative sequences of consumption and capital satisfying the balance condition, $C_{t}+K_{t}=f\left(K_{t-1}\right)$ for all $t$ with $K_{0}=k_{0}$, are bounded from above by $B$.

A feasible capital stock program $\left\{K_{t}^{\prime}\right\}$ dominates the feasible capital stock program $\left\{K_{t}\right\}$, with $K_{t} \neq K_{t}^{\prime}$ for some $t$, if the corresponding consumption program, $\left\{C_{t}^{\prime}\right\}$ has the property: $C_{t}^{\prime} \geq C_{t}$ for all $t$, with strict inequality for some $t$. A feasible capital stock program which is dominated is called inefficient; otherwise, it is said to be efficient.

Associated to any feasible capital program $\left\{K_{t}\right\}$, where $K_{t}>0$ for all $t \geq 1$, is a sequence of shadow prices $\left\{p_{t}\right\}$, or competitive prices, which are recursively defined by

$$
p_{0}=1, \quad p_{t+1} f^{\prime}\left(K_{t}\right)=p_{t}, \quad t \geq 0 .
$$

These prices are also the ones implied or derived from $\left\{K_{t}\right\}$. Note that such a price sequence has 
the property (given $f$ is concave):

$$
p_{t+1} f\left(K_{t}\right)-p_{t} K_{t} \geq p_{t+1} f(x)-p_{t} x \quad \text { for each } x \geq 0 \text { and each } t \geq 0 \text {. }
$$

This is the period-wise (or intertemporal) profit maximizing condition. The prices defined in this manner are strictly positive as $K_{t}>0$ for each $t$.

In general, a sequence $\left\{K_{t}, p_{t}\right\}$ is intertemporal profit maximizing if $\left\{K_{t}\right\}$ is a feasible capital program starting from $k_{0}>0,\left\{p_{t}\right\}$ is a non-null, nonnegative price sequence, and (IPM) obtains for each $t \geq 0$.

Starting with Malinvaud (1953) many authors have shown a close connection between shadow prices and ascertaining whether or not the underlying feasible program is efficient. We note two basic results below.

The Malinvaud Sufficiency Theorem (Malinvaud (1953)) is

Theorem 1. Assume $f$ satisfies AI. If a sequence $\left\{K_{t}, p_{t}\right\}$ is intertemporal profit maximizing, with $p_{t}>0$ for each $t \geq 0$, and

$$
\lim _{t \rightarrow \infty} p_{t} K_{t}=0
$$

then $\left\{K_{t}\right\}$ is efficient.

It is sufficient to verify $p_{t} \rightarrow 0$ as $t \rightarrow \infty$ for the models appearing in this paper. The complete characterization result of Cass (1972) is

Theorem 2. Assume $f$ satisfies AI. Let $\left\{K_{t}\right\}$ be a feasible program from $k_{0}>0$, satisfying:

$$
\inf _{t \geq 0} K_{t}>0,
$$

and let $\left\{p_{t}\right\}$ be the associated price sequence defined by $(\mathbb{P})$. Then, $\left\{K_{t}\right\}$ is inefficient if and only if

$$
\sum_{t=0}^{\infty} \frac{1}{p_{t}}<\infty
$$

\section{The Ramsey Equilibrium Model}

The general complete market competitive one-sector model treats budget constraints as restricting the present value of an agent's consumption to be smaller than or equal to the agent's initial wealth defined as the capitalized wage income plus the present value of that person's initial capital. This allows us to interpret the choice of a consumption stream as if the agent is allowed to borrow and lend at market determined present value prices subject to repaying all loans. Markets are complete - any intertemporal trade satisfying the present value budget constraint is admissible at the individual level.

The Ramsey equilibrium model changes the budget constraint from a single one (reckoned as a present value) to a sequence, one for each period. Agents are forbidden to borrow against their future labor income, so they cannot capitalize the future wage stream into a present value. Markets are incomplete; individuals are debt constrained. The operation of a borrowing constraint in the individual household problems also breaks the possibility of an equilibrium allocation arising as the economy's Pareto optimal allocation. 


\subsection{The Basic Model}

There are $H \geq 1$ households indexed by $h=1, \cdots, H$. There is a single commodity available for consumption or investment at each time. At time zero, households are endowed with capital stocks $k^{h} \geq 0$. Put $k_{0}=\sum_{h} k^{h}$ and assume $k_{0}>0$. Let $c_{t}^{h}, x_{t}^{h}$ denote the consumption and capital stock of household $h$ at time $t$.

Agents preferences assume time additively separable utility functions with fixed discount factors. Household $h$ has felicity function $u_{h} ; c_{t}^{h}$ is the argument of $u_{h}$. Household $h$ discounts future utilities by the factor $\delta_{h}$ with $0<\delta_{h}<1$. Hence, the household's lifetime utility function is specified by $\sum_{t=1}^{\infty} \delta_{h}^{t-1} u_{h}\left(c_{t}^{h}\right)$.

Assumption II: For each $h, u_{h}: \mathbb{R}_{+} \rightarrow \mathbb{R}$ is continuous, increasing and concave on $\mathbb{R}_{+}$and $\mathscr{C}^{(2)}$ on $\mathbb{R}_{++}$with $u_{h}^{\prime}>0, u_{h}^{\prime \prime}<0$ on $\mathbb{R}_{++}$and $\lim _{c \rightarrow 0} u_{h}^{\prime}(c)=\infty$.

We focus on the case where the first household's discount factor is larger than all the other households' discount factors. Assumption III orders households from the most patient to the least patient.

Assumption III: $1>\delta_{1}>\delta_{2} \geq \cdots \geq \delta_{H}>0$.

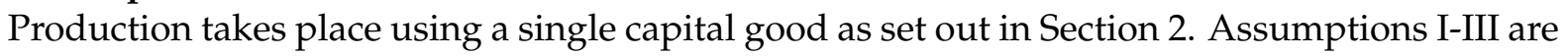
maintained for the remainder of this paper and sometimes referred to as (AI)-(AIII). If $H=1$, then the Ramsey equilibrium model coincides with the standard optimal growth problem. We assume $H \geq 2$ in the sequel.

\subsection{The Households' Problems}

Let $\left\{1+r_{t}, w_{t}\right\}$ be a sequence of one period rental returns and wage rates, respectively. The sequences $\left\{1+r_{t}, w_{t}\right\}$ are always taken to be nonnegative and nonzero. Households are competitive agents and perfectly anticipate the profile of factor returns $\left\{1+r_{t}, w_{t}\right\}$. Given $\left\{1+r_{t}, w_{t}\right\}, h$ solves

$$
P(h): \quad \sup \sum_{t=1}^{\infty} \delta_{h}^{t-1} u_{h}\left(c_{t}^{h}\right)
$$

by choice of nonnegative sequences $\left\{c_{t}^{h}, x_{t}^{h}\right\}$ satisfying $x_{0}^{h}=k^{h}$ and

$$
c_{t}^{h}+x_{t}^{h}=w_{t}+\left(1+r_{t}\right) x_{t-1}^{h} ; \quad t=1,2, \cdots .
$$

The market structure of this model requires capital assets to be nonnegative at each moment of time and that agents without capital cannot borrow against the discounted value of their future wage income.

The No Arbitrage or Euler necessary conditions for $\left\{c_{t}^{h}, x_{t}^{h}\right\}$ to solve $P(h)$ are $c_{t}^{h}>0$ and

$$
\delta_{h}\left(1+r_{t+1}\right) u_{h}^{\prime}\left(c_{t+1}^{h}\right) \leq u_{h}^{\prime}\left(c_{t}^{h}\right)
$$

If $x_{t}^{h}>0$, then the inequality in (Euler IE) can be reversed resulting in the Euler equation:

$$
\delta_{h}\left(1+r_{t+1}\right) u_{h}^{\prime}\left(c_{t+1}^{h}\right)=u_{h}^{\prime}\left(c_{t}^{h}\right)
$$

The corresponding transversality condition is:

$$
\lim _{t \rightarrow \infty} \delta_{h}^{t-1} u_{h}^{\prime}\left(c_{t}^{h}\right)=0
$$

which also implies $\lim _{t \rightarrow \infty} \delta_{h}^{t-1} u_{h}^{\prime}\left(c_{t}^{h}\right) x_{t-1}^{h}=0$ since $\left\{x_{t-1}^{h}\right\}$ is a bounded sequence. 


\subsection{The Production Sector's Objective}

All the intertemporal decisions are taken in the household sector. Producers are supposed to take the rental rate as given and solve the following myopic profit maximization problem $P(F)$ at each $t$ :

$$
P(F): \quad \sup \left[f\left(x_{t-1}\right)-\left(1+r_{t}\right) x_{t-1}\right],
$$

by choice of $x_{t-1} \geq 0$. The residual profit is treated as the wage bill. It is shared equally by the identical households as wages - production is worker owned.

If $0<1+r_{t}<\infty$, then $(A I)$ implies there is a unique positive stock $K_{t-1}$ which solves $P(F)$ at each $t$; clearly

$$
f^{\prime}\left(K_{t-1}\right)=1+r_{t}
$$

furthermore, the corresponding $\left\{w_{t}\right\}$ is positive and is defined by

$$
H w_{t}=f\left(K_{t-1}\right)-\left(1+r_{t}\right) K_{t-1} .
$$

\subsection{The Ramsey Economy and Its Equilibrium Concept}

A collection $\mathscr{E}=\left(f,\left\{u_{h}, \delta_{h}, k^{h}\right\}, h=1,2, \cdots, H\right)$ satisfying Assumptions I-III, and for which $k^{h} \geq 0$ for each $h$ with $k_{0}=\sum_{h=1}^{H} k^{h}>0, k_{0} \leq B$, is said to be an economy. The economy always has a positive aggregate capital stock and at least one agent will always possess some capital at time zero.

The equilibrium concept is perfect foresight. Households perfectly anticipate the sequences of rental and wage rates. They solve their optimization problems for their planned consumption demand and capital supply sequences. The production sector calculates the capital demand at each time and the corresponding total output supply. Rents are paid to the households for capital supplied and the residual profits are paid out as the total wage bill. An equilibrium occurs when the households' capital supply equals the production sector's capital demand at every point of time. A form of Walras' Law implies that the total consumption demand and supply of capital for the next period equals current output. Thus, in equilibrium, every agent is maximizing its objective function and planned supplies equal planned demands in every market.

Definition 1. Sequences $\left\{1+r_{t}, w_{t}, K_{t-1}, c_{t}^{h}, x_{t-1}^{h}\right\}$ constitute a Ramsey Equilibrium for a given economy $\mathscr{E}$ provided:

(E1) For each $h,\left\{c_{t}^{h}, x_{t-1}^{h}\right\}$ solves $P(h)$ given $\left\{1+r_{t}, w_{t}\right\}$.

(E2) For each $t, K_{t-1}$ solves $P(F)$ given $1+r_{t}$.

(E3) $H w_{t}=f\left(K_{t-1}\right)-\left(1+r_{t}\right) K_{t-1}$ for $t=1,2, \cdots$.

(E4) $\sum_{h=1}^{H} x_{t-1}^{h}=K_{t-1}$ for $t=1,2, \cdots$, and $0<k_{0}=K_{0} \leq B$.

The output market balance follows by combining (E1) - (E4):

$$
\sum_{h=1}^{H}\left(c_{t}^{h}+x_{t}^{h}\right)=f\left(K_{t-1}\right) .
$$

Note that equilibrium consumption and capital sequences are bounded from above by the maximum sustainable stock. The assumed conditions for households and the producer imply that in an equilibrium $c_{t}^{h}>0$ and $K_{t-1}>0$ for each $t$, given that $k_{0}$ is positive, and each agent's income, $w_{t}+\left(1+r_{t}\right) x_{t-1}^{h}>0$ at each time, even if $x_{t-1}^{h}=0$. Moreover, at least one household's capital stock is positive at each time along an equilibrium profile.

Given an equilibrium path, the corresponding aggregate capital sequence and consumption sequence are defined by the formulas $K_{t}=\sum_{h=1}^{H} x_{t}^{h}$ and $C_{t}=\sum_{h=1}^{H} c_{t}^{h}$, respectively. 


\section{Properties of Ramsey Equilibria}

A Ramsey equilibrium program is stationary for the economy $\mathscr{E}$ provided the equilibrium wage rate, rental rate, the aggregate capital stock, and the allocations of capital and consumption are constant over time. Becker (1980) proves the existence of a unique stationary equilibrium in which only the most patient household has capital - all other households have none and live off their wage incomes.

Let $K^{\delta_{1}}$ be the unique solution to the equation $f^{\prime}(k)=\left(1 / \delta_{1}\right)$. This capital stock is the first household's capital and the stationary aggregate capital stock in the stationary equilibrium solution. Stationary aggregate consumption is found at each time by adding the economy's wage bill to the rental income received by the most patient household.

General properties of equilibrium paths found under Assumptions I-III are briefly summarized below. Fix the economy $\mathscr{E}$ meeting Assumptions (I-III).

(P1) Equilibria exist ${ }^{3}$.

(P2) If $\left\{1+r_{t}, w_{t}, K_{t-1}, c_{t}^{h}, x_{t-1}^{h}\right\}$ is a Ramsey equilibrium for $\mathscr{E}$, then the no capital state is recurrent for each $h \geq 2$. That is, for each $h \geq 2, x_{t}^{h}=0$ infinitely often ${ }^{⿴ 囗 十}$.

This Recurrence Theorem is the most general result in the literature on the properties enjoyed in a dynamic Ramsey equilibrium. It tells us households $h \geq 2$ achieve the zero capital state infinitely often. There are equilibria where agents more impatient than the first hold capital infinitely often. See Stern's example in Becker (2006).

The turnpike property obtains if every $h \geq 2$ eventually reaches a no capital position and maintains that state thereafter. That is, there is some $S \in \mathbb{N}$ such that for each $h \geq 2, x_{t}^{h}=0$ for all $t \geq S$. Stern's example implies the turnpike property does not hold for all Ramsey Equilibria.

(P3) For each equilibrium, $\limsup _{t \rightarrow \infty} K_{t-1} \geq K^{\delta_{1}}$.

This result does not exclude the capital sequence from exceeding the Golden-Rule capital stock, $K^{g}$, infinitely often, where $K^{g}$ is defined as the solution to $f^{\prime}(k)=1$.

(P4) Each household's consumption is bounded away from zero along an equilibrium path. That is, $\eta^{h} \equiv \inf _{t} c_{t}^{h}>0$ for $h=1,2, \cdots, H$ holds in each equilibrium ${ }^{\square}$

Property (P4) implies no agent consumes zero or even approaches zero consumption asymptotically. This result distinguishes the Ramsey model with borrowing constraints from its complete market general equilibrium counterparts.

\subsection{Convergence and the Turnpike Property}

We have noted above that the turnpike property on the capital ownership pattern does not always hold for Ramsey Equilibria. However, if the capital stock sequence along a Ramsey equilibrium path converges, then the turnpike property on the ownership pattern of capital holds, a result due to Becker and Foias (1987).

Theorem 3. Let $\left\{1+r_{t}, w_{t}, K_{t-1}, c_{t}^{h}, x_{t-1}^{h}\right\}$ be a Ramsey equilibrium, such that $\left\{K_{t-1}\right\}$ is convergent. Then, there is $S \in \mathbb{N}$ such that for every $h \in\{2, \cdots, H\}, x_{t}^{h}=0$ for all $t \geq S$.

\footnotetext{
${ }^{3}$ See Becker et al. (1991) for general existence theorems that apply to the additive separable utility cases in this paper, as well as for broader recursive utility specifications.

${ }^{4}$ See Becker and Foias (1987).

${ }^{5} \mathrm{~A}$ formal proof of this fact is available on request from Robert Becker as a Technical Appendix.
} 
Given this result, one can seek restrictions on the primitives of the model under which the capital stock sequence is convergent for Ramsey Equilibria. When the production function satisfies a capital income monotonicity condition, it is known (see Becker and Foias (1987)) that the capital stock sequence along every Ramsey Equilibrium path is convergent. The capital income monotonicity condition is

$$
f^{\prime}(K) K \text { increases in } K \text { for all } K>0 .
$$

Proposition 1. Let $\left\{1+r_{t}, w_{t}, K_{t-1}, c_{t}^{h}, x_{t-1}^{h}\right\}$ be a Ramsey equilibrium, and let $f$ satisfy condition (CIM). Then,

(i) $\left\{K_{t-1}\right\}$ is convergent, and

(ii) there is $S \in \mathbb{N}$ such that for every $h \in\{2, \cdots, H\}, x_{t}^{h}=0$ for all $t \geq S$.

In this subsection, we establish the result that under a maximal income monotonicity condition on the production function, the capital stock sequence is convergent, and consequently the turnpike property holds. The maximal income monotonicity condition generalizes the capital income monotonicity condition.

The maximal income that a single household can receive in a period, in which the initial capital stock is $K>0$, is given by:

$$
M(K) \equiv f^{\prime}(K) K+\frac{\left[f(K)-K f^{\prime}(K)\right]}{H} .
$$

This happens when that household owns the entire initial capital stock $K$ in that period.

The maximal income monotonicity condition is ${ }^{\text {b }}$

$$
M(K) \text { increases in } K \text { for all } K>0 .
$$

Since $f^{\prime \prime}<0$ for $K>0$, we know that $\left\{\left[f(K)-K f^{\prime}(K)\right] / H\right\}$ increases in $K$ for $K>0$. Thus, if the

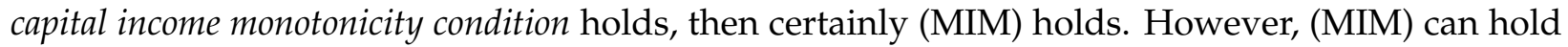
even when (CIM) fails.

Among commonly used production functions, the capital income monotonicity condition is satisfied by the Cobb-Douglas production function. The maximal income monotonicity condition is satisfied, in addition, by a subclass of production functions with lower elasticity of substitution than the Cobb-Douglas case.

Our approach is to look at the implications of non-convergence of capital stocks along a Ramsey Equilibrium path. Specifically, we note that if the capital stock exceeds $K^{\delta_{1}}$ for a subsequence of periods, then among these periods there must be one where the capital stock attains a "local maximum".

Lemma 1. Let $\left\{1+r_{t}, w_{t}, K_{t-1}, c_{t}^{h}, x_{t-1}^{h}\right\}$ be a Ramsey equilibrium, such that $\left\{K_{t-1}\right\}$ is not convergent. Suppose there is a subsequence of periods for which $\delta_{1} f^{\prime}\left(K_{t}\right)<1$. Then there is $N \in \mathbb{N}$ such that:

(i) $K_{N-1} \leq K_{N} ; \quad K_{N+1}<K_{N}$ ，

\footnotetext{
${ }^{6}$ Becker and Foias (1990) call condition (MIM) the Income Monotonicity Condition. They introduce the condition to study the dynamics of a Ramsey Equilibrium which satisfies the turnpike property, and show that when (IMIMI) holds, then the dynamics is characterized by monotonic convergence. Thus, in their analysis, after a finite time period, $M\left(K_{t}\right)$ is the income of the first household, so the term Income Monotonicity is natural in that context. We do not assume the turnpike property; we use condition $(\mathbb{M I M})$ to establish the turnpike property. So, we use the term maximal income monotonicity instead, since $M(K)$ need not actually represent the income of any particular household (at least until the turnpike property has been established).
} 
(ii) $\delta_{1} f^{\prime}\left(K_{N}\right)<1$.

If the production function satisfies ( $(\mathrm{M} / \mathrm{M})$, then it rules out precisely this kind of "local maximum".

Lemma 2. Let $\left\{1+r_{t}, w_{t}, K_{t-1}, c_{t}^{h}, x_{t-1}^{h}\right\}$ be a Ramsey equilibrium, and let $f$ satisfy condition (MIM). If there is $N \in \mathbb{N}$ such that:

$$
K_{N-1} \leq K_{N} ; \quad K_{N+1}<K_{N}
$$

then:

$$
\delta_{1} f^{\prime}\left(K_{N}\right)>1 .
$$

Combining these two results, it follows that, under condition (MMㄱ), either a Ramsey Equilibrium path is (i) convergent, or (ii) its capital stock sequence is eventually always less than or equal to $K^{\delta_{1}}$. However, the latter scenario itself also implies convergence, as can be verified easily from the Euler inequalities.

Theorem 4. Let $\left\{1+r_{t}, w_{t}, K_{t-1}, c_{t}^{h}, x_{t-1}^{h}\right\}$ be a Ramsey equilibrium, and let $f$ satisfy condition (MIM). Then,

(i) $\left\{K_{t-1}\right\}$ is convergent, and

(ii) there is $S \in \mathbb{N}$ such that for every $h \in\{2, \ldots, H\}$, $x_{t}^{h}=0$ for all $t \geq S$.

\subsection{Comparison of Conditions CIM and MIM}

The difference between the $(\mathrm{MIM})$ and $(\mathrm{CIM})$ conditions can be expressed conveniently in terms of the second elasticity of the production function, $f(K)$.

Define $G(K)=f^{\prime}(K) K$ for $K>0$, and note that:

$$
G^{\prime}(K)=f^{\prime}(K)+K f^{\prime \prime}(K)=f^{\prime}(K)[1-e(K)],
$$

where:

$$
e(K) \equiv \frac{\left[-f^{\prime \prime}(K)\right] K}{f^{\prime}(K)} \quad \text { for all } K>0
$$

is the second elasticity of the production function. Thus, (CIM) holds if and only if:

$$
e(K)<1 \text { for all } K>0 .
$$

On the other hand, defining $M(K) \equiv f^{\prime}(K) K+\left\{\left[f(K)-K f^{\prime}(K)\right] / H\right\}$ for $K>0$, we see that:

$$
\begin{aligned}
M^{\prime}(K) & =\frac{\left[-f^{\prime \prime}(K)\right] K}{H}+f^{\prime}(K)+K f^{\prime \prime}(K) \\
& =f^{\prime}(K)[1-e(K)\{1-(1 / H)\}] .
\end{aligned}
$$

Thus, (MUM) holds if and only if:

$$
e(K)\{1-(1 / H)\}<1 \quad \text { for all } K>0 .
$$

Since $f(K)$ is a reduced form production function, derived from a constant returns to scale production function $F(K, L)$ on capital and labor, the second elasticity of $f$ can be related to the elasticity of substitution of $F$ through the formula:

$$
e(K)=\frac{1}{\sigma(K)}\left[1-\frac{K f^{\prime}(K)}{f(K)}\right] .
$$


Since $\left[K f^{\prime}(K) / f(K)\right] \in(0,1)$, ((M)M) holds if:

$$
\sigma(K) \geq 1-(1 / H) \text { for all } K>0,
$$

while (CIM) holds if:

$$
\sigma(K) \geq 1 \quad \text { for all } K>0 \text {. }
$$

In Appendix $\mathrm{C}$, we provide an example of an approximate CES production function satisfying the (MUM) condition.

\subsection{Weak Turnpike Property and Efficiency}

The study of the capital ownership pattern along a Ramsey Equilibrium path focuses, as we have seen, on the turnpike property. While the efficiency of Ramsey Equilibria appears to be linked to the capital ownership pattern, it seems to be more directly related to the weak turnpike property. The principal result on this issue is the following one, due to Becker and Mitra (2012).

Theorem 5. Let $\left\{1+r_{t}, w_{t}, K_{t-1}, c_{t}^{h}, x_{t-1}^{h}\right\}$ be a Ramsey equilibrium, which satisfies the property that there is $S \in \mathbb{N}$, such that

$$
x_{t-1}^{1}>0 \text { for all } t \geq S \text {. }
$$

Then, $\left\{K_{t-1}\right\}$ is efficient.

Thus, any Ramsey Equilibrium path which satisfies the weak turnpike property is always efficient. And, by Theorem B, any Ramsey Equilibrium path along which the capital stock sequence converges is efficient. However, Theorem $\square$ also applies to Ramsey Equilibria for which the capital stock sequence does not converge. One naturally thinks of a period-two cycle as the simplest example of non-convergence. And, it is of interest to note that every period two Ramsey Equilibrium cycle is efficient, because any such cycle can be shown to satisfy the weak turnpike property.

A Ramsey Equilibrium $\left\{\left(1+r_{t}\right), w_{t}, K_{t-1}, c_{t}^{h}, x_{t-1}^{h}\right\}$ is a period two Ramsey Equilibrium cycle if there exist $\hat{x}$ and $\bar{x}$ in $\mathbb{R}_{+}^{H}$ with $\hat{x} \neq \bar{x}$, such that:

$$
x_{t} \equiv\left(x_{t}^{1}, \cdots, x_{t}^{H}\right)= \begin{cases}\hat{x} & \text { for } t=0,2,4, \cdots \\ \bar{x} & \text { for } t=1,3,5, \cdots\end{cases}
$$

Corollary 1. Let $\left\{\left(1+r_{t}\right), w_{t}, K_{t-1}, c_{t}^{h}, x_{t-1}^{h}\right\}$ be a period two Ramsey Equilibrium cycle. Then,

(a) $x_{t}^{1}>0$ for all $t \geq 0$, and

(b) the Ramsey Equilibrium is efficient.

In particular, in Stern's example, reported in Becker (2006), there is a period two Ramsey Equilibrium cycle, in which the turnpike property on the capital ownership pattern is violated, since the impatient household holds capital in alternate periods. But, since the patient household holds capital in all periods, the weak turnpike property holds, and the Ramsey Equilibrium is efficient.

\section{Inefficient Ramsey Equilibrium}

The results reported in the previous section indicate that a basic unresolved question is whether Ramsey Equilibria always satisfy the weak turnpike property. We settle this issue by providing an example of a Ramsey Equilibrium in which the most patient household reaches a no capital position infinitely often (in fact, periodically, since our example is of a cyclic Ramsey equilibrium), and the Ramsey Equilibrium is inefficient. 


\subsection{Period Three Inefficient Ramsey Equilibrium: Necessary Conditions}

Our approach to constructing the example mentioned above is to first study the necessary conditions for an inefficient Ramsey equilibrium to occur. We expect these conditions to be especially restrictive in the case of inefficient Ramsey equilibrium cycles. This can be helpful as it can pin down both the nature of the program as well as the required restrictions on the primitives (preferences, technology, discount factors) of the model.

In view of the Becker and Mitra (2012) result on period-two Ramsey Equilibrium cycles, we examine the necessary conditions for a period three Ramsey Equilibrium cycle to exist and be inefficient. The choice of period three is dictated by the observation that if an example can be constructed of an inefficient Ramsey equilibrium cycle, then an attempt to show this in the period three case will involve verifying a minimal number of Ramsey-Euler inequalities and feasibility conditions. Furthermore, and for the same reason, we confine ourselves to the case of two households.

We consider a model specified by $\left\{f, u_{1}, u_{2}, \delta_{1}, \delta_{2}\right\}$ with $\delta_{2}<\delta_{1}<1$. A Ramsey Equilibrium $\left\{\left(1+r_{t}\right), w_{t}, K_{t-1}, c_{t}^{h}, x_{t-1}^{h}\right\}$ is a period three Ramsey Equilibrium cycle if there exist three distinct vectors $A, B, C$ in $\mathbb{R}_{+}^{2}$, such that:

$$
x_{t} \equiv\left(x_{t}^{1}, x_{t}^{2}\right)= \begin{cases}A & \text { for } t=0,3,6, \cdots \\ B & \text { for } t=1,4,7, \cdots \\ C & \text { for } t=2,5,8, \cdots\end{cases}
$$

Denote by $A^{\prime}, B^{\prime}, C^{\prime}$ the aggregate capital stocks corresponding to the vectors $A, B, C$. Let $M$ be the maximum of $\left\{A^{\prime}, B^{\prime}, C^{\prime}\right\}$. Pick the smallest $T \geq 2$, such that $K_{T}=M$. Then, we have $K_{T-1} \leq K_{T}$ and $K_{T+1} \leq K_{T}$.

Proposition 2. Let $\left\{\left(1+r_{t}\right), w_{t}, K_{t-1}, c_{t}^{h}, x_{t-1}^{h}\right\}$ be a period three Ramsey Equilibrium cycle, which is inefficient. Pick $T \geq 2$ as indicated above. Then:

(a) $K_{T}>K_{T+1}>K^{g}>K_{T-1}$;

(b) $x_{T}^{1}=K_{T}$ and $x_{T+1}^{2}=K_{T+1}$;

(c) $\delta_{2}<\left(\delta_{1}\right)^{4}$;

(d) $c_{T-1}^{1}<c_{T+1}^{1}<c_{T}^{1}$;

(e) $c_{T+1}^{2}>\max \left\{c_{T}^{2}, c_{T-1}^{2}\right\}$;

(f) $\delta_{2}<\sqrt{2}-1 \approx 0.414$.

\subsection{Period Three Inefficient Ramsey Equilibrium: An Example}

Taking into account the restrictions provided in Proposition $\square$, we now construct an example of a period-three Ramsey equilibrium cycle which is inefficient; as indicated already in the proposition, the equilibrium has the feature that the patient household owns no capital periodically. The production function in the example is not smooth, but it can be smoothened out while preserving all its features. 


\subsection{Production}

The production function is defined in four parts as follows: Let $a>1>b>d>0$ be such that $a b d<1$ and $\theta>0$. We choose $c=\frac{1}{4 a}$ and $\mu=\frac{1}{4 a^{2}}=4 c^{2}$ to ensure that $f$ is continuous at $\mu$ and the derivative of $f$ exists at $\mu$.

$$
f(x)= \begin{cases}\sqrt{x} & \text { for } x \in[0, \mu] \\ c+a x & \text { for } x \in[\mu, 1] \\ c+a+b(x-1) & \text { for } x \in[1,1+\theta] \\ c+a+b \theta+d(x-1-\theta) & \text { for } x \geq 1+\theta .\end{cases}
$$

In what follows, we assume following parameter values, $a=175, b=\frac{3}{36}, d=\frac{1}{36}$, and $\theta=40$ which gives us $c=\frac{1}{4 a}=\frac{1}{700}$ and $\mu=\frac{1}{4 a^{2}}=\frac{1}{350^{2}}$. Thus $f$ can be written as:

$$
f(x)= \begin{cases}\sqrt{x} & \text { for } x \in[0, \mu] \\ c+175 x & \text { for } x \in[\mu, 1] \\ c+175+\frac{3}{36}(x-1) & \text { for } x \in[1,41] \\ c+178+\frac{1}{3}+\frac{1}{36}(x-41) & \text { for } x \geq 41 .\end{cases}
$$

We check the following steps.

(a) We have $f(0)=0$, and $f^{\prime}(x) \rightarrow \infty$ as $x \rightarrow 0$. Further, $f(\mu)=\sqrt{\mu}=\frac{1}{350}$. Since $f^{\prime}(x)=\frac{1}{2 \sqrt{x}}$ for $0<x \leq \mu$ we have $f_{-}^{\prime}(\mu)=175$.

(b) We have $f_{-}(\mu)=\frac{1}{350}$ and $f_{+}(\mu)=\frac{1}{700}+175 \cdot \frac{1}{350^{2}}=\frac{1}{700}+\frac{1}{700}=\frac{1}{350}=f_{-}(\mu)$. Further, $f_{+}^{\prime}(\mu)=175=$ $f_{-}^{\prime}(\mu)$. And, $f(1)=c+175$, with $f_{-}^{\prime}(1)=175$.

(c) We have $f_{+}(1)=c+175=f_{-}(1)$. Further, $f_{+}^{\prime}(x)=\frac{3}{36}$ for $1<x \leq 41$ so $f_{+}^{\prime}(1)=\frac{3}{36}<175=f_{-}^{\prime}(1)$. Also, $f(41)=c+175+\frac{3}{36} \cdot 40=c+178+\frac{1}{3}$, with $f_{-}^{\prime}(41)=\frac{3}{36}$.

(d) We have $f_{+}(41)=c+178+\frac{1}{3}=f_{-}(41)$. Further, $f_{+}^{\prime}(x)=\frac{1}{36}$ for all $x>41$, so $f_{+}^{\prime}(41)=\frac{1}{36}<\frac{3}{36}=f_{-}^{\prime}(41)$.

To summarize, $f(0)=0, f$ is continuous, strictly increasing and concave $\left(f_{+}^{\prime}(x)\right.$ is non-increasing for all $x>0$ ). Further, we have $f^{\prime}(x) \rightarrow \infty$ as $x \rightarrow 0$, and $f^{\prime}(x)=\frac{1}{36}<1$ for all $x>41$. In particular, feasible programs from any given initial stock are bounded above.

\subsection{Program}

We define:

$$
\alpha=\frac{174}{175}, \quad \beta=42, \quad \gamma=\frac{40}{39} .
$$

We can then check the following steps.

(a) We have $f(\alpha)=c+175(\alpha)=c+174$. Also $f^{\prime}(\alpha)=175$ and $\alpha f^{\prime}(\alpha)=174$, so that $\left[f(\alpha)-\alpha f^{\prime}(\alpha)\right]=$ $c>0$.

(b) We have $f(\beta)=f(42)=c+178+\frac{1}{3}+\frac{1}{36}(42-41)=c+178+\frac{13}{36}$. Also, $f^{\prime}(\beta)=\frac{1}{36}$, and $f^{\prime}(\beta) \beta=\frac{1}{36} \cdot 42=$ $\frac{7}{6}$, so that $\left[f(\beta)-\beta f^{\prime}(\beta)\right]=c+178+\frac{13}{36}-\frac{42}{36}=c+178-\frac{29}{36}$.

(c) We have $f(\gamma)=f\left(\frac{40}{39}\right)=c+175+\frac{3}{36} \cdot \frac{1}{39}=c+175+\frac{1}{13 \cdot 36}$. Also, $f^{\prime}(\gamma)=\frac{3}{36}$, and $f^{\prime}(\gamma) \gamma=\frac{3}{36} \cdot \frac{40}{39}=\frac{40}{13 \cdot 36}$, so that $\left[f(\gamma)-f^{\prime}(\gamma) \gamma\right]=c+175-\frac{1}{12}$. 
Now, define the program as follows:

$$
\left.\begin{array}{lllll}
K_{T-1}=\alpha, & x_{T-1}^{1}=\alpha, & x_{T-1}^{2}=0 \\
K_{T}=\beta, & x_{T}^{1}=\beta, & x_{T}^{2} & =0 \\
K_{T+1} & =\gamma, & x_{T+1}^{1}=0, & x_{T+1}^{2} & =\gamma
\end{array}\right\}
$$

Then, we have the corresponding consumption sequence defined by:

$$
\left.\begin{array}{l}
c_{T}^{1}=\frac{f(\alpha)-\alpha f^{\prime}(\alpha)}{2}+\alpha f^{\prime}(\alpha)-\beta=\frac{c}{2}+174-42=\frac{c}{2}+132 \\
c_{T}^{2}=\frac{f(\alpha)-\alpha f^{\prime}(\alpha)}{2}=\frac{c}{2}
\end{array}\right\}
$$

and

$$
\left.\begin{array}{l}
c_{T+1}^{1}=\frac{f(\beta)-\beta f^{\prime}(\beta)}{2}+\beta f^{\prime}(\beta)=\frac{c+178-\frac{29}{36}}{2}+\frac{42}{36}=\frac{c}{2}+89+\frac{55}{72} \\
c_{T+1}^{2}=\frac{f(\beta)-\beta f^{\prime}(\beta)}{2}-\gamma=\frac{c+178-\frac{29}{36}}{2}-\frac{40}{39}=\frac{c}{2}+87+\frac{43}{72}-\frac{1}{39}
\end{array}\right\} ;
$$

and

$$
\left.\begin{array}{l}
c_{T-1}^{1}=c_{T+2}^{1}=\frac{f(\gamma)-\gamma f^{\prime}(\gamma)}{2}-\alpha=\frac{c+175-\frac{1}{12}}{2}-\frac{174}{175}=\frac{c}{2}+86+\frac{1}{175}+\frac{11}{24} \\
c_{T-1}^{2}=c_{T+2}^{2}=\frac{f(\gamma)-\gamma f^{\prime}(\gamma)}{2}+\gamma f^{\prime}(\gamma)=\frac{c+175-\frac{1}{12}}{2}+\frac{40}{39} \cdot \frac{3}{36}=\frac{c}{2}+87.5+\frac{41}{13 \cdot 72}
\end{array}\right\} .
$$

Observe that $c_{T+1}^{2}-c_{T+2}^{2}=\frac{c}{2}+87+\frac{43}{72}-\frac{1}{39}-\left(\frac{c}{2}+87.5+\frac{41}{13 \cdot 72}\right)=\frac{1}{36}>0$. It follows from (II), (ㅁ) and (3) that:

$$
\left.\begin{array}{l}
\text { (i) } c_{T}^{1}>c_{T+1}^{1}>c_{T+2}^{1}=c_{T-1}^{1} \\
\text { (ii) } c_{T+1}^{2}>c_{T+2}^{2}=c_{T-1}^{2}>c_{T}^{2}
\end{array}\right\} \text {. }
$$

\subsection{Preferences}

For household 1 , define $u_{1}: \mathbb{R}_{+} \rightarrow \mathbb{R}$ as an increasing, concave function on $\mathbb{R}_{+}$, differentiable on $\mathbb{R}_{++}$, with $u_{1}^{\prime}(c) \rightarrow \infty$ as $c \rightarrow 0$, and:

$$
u_{1}^{\prime}\left(c_{T}^{1}\right)=1, \quad u_{1}^{\prime}\left(c_{T+1}^{1}\right)=40, \quad u_{1}^{\prime}\left(c_{T+2}^{1}\right)=u_{1}^{\prime}\left(c_{T-1}^{1}\right)=\frac{315}{2} .
$$

Given (4)(i), such a utility function can be constructed. Define the discount factor $\delta_{1}=\frac{9}{10}$.

For household 2, define $u_{2}: \mathbb{R}_{+} \rightarrow \mathbb{R}$ as an increasing, concave function on $\mathbb{R}_{+}$, differentiable on $\mathbb{R}_{++}$, with $u_{1}^{\prime}(c) \rightarrow \infty$ as $c \rightarrow 0$, and:

$$
u_{2}^{\prime}\left(c_{T+1}^{2}\right)=\frac{1}{100}, \quad u_{2}^{\prime}\left(c_{T+2}^{2}\right)=u_{2}^{\prime}\left(c_{T-1}^{2}\right)=24, \quad u_{2}^{\prime}\left(c_{T}^{2}\right)=25 .
$$

Given (4)(ii), such a utility function can be constructed. Define the discount factor $\delta_{2}=\frac{1}{200}$.

\subsection{Ramsey-Euler Conditions}

We can check that the Ramsey-Euler conditions hold for household 1 . Since $x_{T}^{1}>0$, we need to verify that the (EulerE) equation holds between periods $T$ and $T+1$. This is seen as follows.

$$
\frac{u_{1}^{\prime}\left(c_{T+1}^{1}\right)}{u_{1}^{\prime}\left(c_{T}^{1}\right)}=\frac{40}{1}=\frac{1}{\frac{9}{10} \cdot \frac{1}{36}}=\frac{1}{\delta_{1} f^{\prime}\left(K_{T}\right)} .
$$


Since $x_{T-1}^{1}>0$, we need to verify that the (EulerE) equation holds between periods $T-1$ and $T$. This is seen as follows.

$$
\frac{u_{1}^{\prime}\left(c_{T}^{1}\right)}{u_{1}^{\prime}\left(c_{T-1}^{1}\right)}=\frac{1}{\frac{315}{2}}=\frac{2}{315}=\frac{1}{\frac{9}{10} \cdot(175)}=\frac{1}{\delta_{1} f^{\prime}\left(K_{T-1}\right)} .
$$

Finally, since $x_{T+1}^{1}=0$, we need to verify that the Ramsey-Euler inequality holds between periods $(T+1)$ and $(T+2)$. This is seen as follows.

$$
\frac{u_{1}^{\prime}\left(c_{T+2}^{1}\right)}{u_{1}^{\prime}\left(c_{T+1}^{1}\right)}=\frac{315}{2 \cdot(40)}=\frac{63}{16}<\frac{40}{3}=\frac{1}{\left(\frac{9}{10}\right) \cdot\left(\frac{3}{36}\right)}=\frac{1}{\delta_{1} \cdot f^{\prime}\left(K_{T+1}\right)} .
$$

Similarly, we can check the Ramsey-Euler conditions hold for household 2. Since $x_{T+1}^{2}>0$, we need to verify that the (EulerE) equation holds between periods $T+1$ and $T+2$. This is seen as follows.

$$
\frac{u_{2}^{\prime}\left(c_{T+2}^{2}\right)}{u_{2}^{\prime}\left(c_{T+1}^{2}\right)}=\frac{24}{\frac{1}{100}}=2400=\frac{1}{\left(\frac{1}{200}\right)\left(\frac{3}{36}\right)}=\frac{1}{\delta_{2} \cdot f^{\prime}\left(K_{T+1}\right)} .
$$

Since $x_{T}^{2}=0$, we need to verify that the Ramsey-Euler inequality holds between periods $T$ and $T+1$. This is seen as follows.

$$
\frac{u_{2}^{\prime}\left(c_{T+1}^{2}\right)}{u_{2}^{\prime}\left(c_{T}^{2}\right)}=\frac{\frac{1}{100}}{25}=\frac{1}{2500}<\frac{1}{\left(\frac{1}{200}\right)\left(\frac{1}{36}\right)}=\frac{1}{\delta_{2} f^{\prime}\left(K_{T}\right)} .
$$

Finally, since $x_{T-1}^{2}=0$, we need to verify that the Ramsey-Euler inequality holds between periods $(T-1)$ and $T$. This is seen as follows.

$$
\frac{u_{2}^{\prime}\left(c_{T}^{2}\right)}{u_{2}^{\prime}\left(c_{T-1}^{2}\right)}=\frac{25}{24}<\frac{8}{7}=\frac{1}{\left(\frac{1}{200}\right)(175)}=\frac{1}{\delta_{2} f^{\prime}\left(K_{T-1}\right)} .
$$

This completes the demonstration that the defined program constitutes a Ramsey Equilibrium, and that it is a period-three cycle.

\subsection{Inefficiency}

We cannot use the Cass criterion (CC) to demonstrate the inefficiency of the defined program, since the production function $f$ does not satisfy the smoothness conditions used in the theorem of Cass (1972). However, we note that:

$$
f^{\prime}\left(K_{T-1}\right) f^{\prime}\left(K_{T}\right) f^{\prime}\left(K_{T+1}\right)=175 \cdot \frac{3}{36} \cdot \frac{1}{36}=\frac{175}{432}<1,
$$

and that the defined program takes on its capital stock values in the interiors of the three flat sections. Thus, we can follow the basic lemma of Cass (1972, p. 204-205) to demonstrate that the defined program is inefficient. We show the proof in Appendix D.

\section{Conclusion}

The introduction of the Maximal Income Monotonicity (MIM) condition broadens the class of Ramsey equilibrium models whose equilibria are efficient. Our example of inefficiency shows 
that some Ramsey equilibria can be inefficient in the absence of a condition such as MIM. Of course, this immediately implies that the equilibrium profile in our inefficiency example fails the first welfare theorem - a fact that is not surprising on the general grounds that the economy's dynamics are restricted by borrowing constraints. The much more interesting problem is that it also implies that an equilibrium program can fail to be second best even though we do not yet have a formal definition of second best Pareto optimality. Indeed, any reasonable notion of second best Pareto optimality must be consistent with the underlying capital accumulation satisfying the efficiency criterion.

Our formal results partially hinge on the assumption capital is circulating as there is 100 percent depreciation within a period. Becker et al. (2012) show in a model with endogenous labor supply that there is a role for a low, but nonzero, depreciation rate and durable capital in proving an equilibrium path might be efficient. It would be interesting to examine their results within our framework, both with the inelastic labor supply model studied here, as well as one with variable labor supply and circulating capital.

\section{Appendix: Proofs}

\section{A Proof of Theorem 4}

Proof. of Lemma til: Since $\left\{K_{t-1}\right\}$ is not convergent, we have:

$$
a \equiv \limsup _{t \rightarrow \infty} K_{t}>\liminf _{t \rightarrow \infty} K_{t} \equiv b .
$$

Denote $(a-b)$ by $\theta$. Since $\liminf _{t \rightarrow \infty} K_{t}=b$, we can pick $T_{1}=\min \left\{t \in \mathbb{N}: K_{t}<b+\frac{\theta}{3}\right\}$. Since there is a subsequence of periods for which $\delta_{1} f^{\prime}\left(K_{t}\right)<1$, we have $K_{t}>K^{\delta_{1}}$ for that subsequence of periods. So, we can pick $T_{2}=\min \left\{t \in \mathbb{N}: t>T_{1}\right.$ such that $\left.K_{t}>K^{\delta_{1}}\right\}$. Since $a=\limsup _{t \rightarrow \infty} K_{t}$, we can pick $T_{3}=$ $\min \left\{t \in \mathbb{N}: t>T_{2}\right.$ such that $\left.K_{t}>a-\frac{\theta}{3}\right\}$. And, since $\liminf _{t \rightarrow \infty} K_{t}=b$, we can pick $T_{4}=\min \{t \in \mathbb{N}: t>$ $T_{3}$ such that $\left.K_{t}<b+\frac{\theta}{3}\right\}$. Define $m=\max \left\{K_{t}: T_{1} \leq t \leq T_{4}\right\}$. Then,

$$
\begin{aligned}
\text { (i) } & m>K^{\delta_{1}} \\
\text { (ii) } & m>a-(\theta / 3)>b+(\theta / 3) .
\end{aligned}
$$

Now define $N=\max \left\{T_{1} \leq t \leq T_{4}: K_{t}=m\right\}$. Then, using (A.1)(ii), we have $N<T_{4}$ and $N>T_{1}$. Further, by definition of $m$, we have $K_{N-1} \leq K_{N}$ and by definition of $N$, we have $K_{N+1}<K_{N}$. Also, by (A.1)(i), $K_{N}>K^{\delta_{1}}$ and so $\delta_{1} f^{\prime}\left(K_{N}\right)<1$. This completes the proof of the Lemma.

Proof. of Lemma 2: Suppose the condition $K_{N-1} \leq K_{N}$ and $K_{N+1}<K_{N}$ is satisfied for some $N \in \mathbb{N}$, but the condition $\delta_{1} f^{\prime}\left(K_{N}\right)>1$ is violated. Then

$$
\delta_{1} f^{\prime}\left(K_{N}\right) \leq 1 .
$$

Let $\Gamma=\left\{h \in\{1, \cdots, H\}: x_{N}^{h}>0\right\}$. Denote the cardinality of $\Gamma$ by $\gamma$. Then for each $h \in \Gamma$, by (A.2),

$$
\frac{u_{h}^{\prime}\left(c_{N+1}^{h}\right)}{u_{h}^{\prime}\left(c_{N}^{h}\right)}=\frac{1}{\delta_{h} f^{\prime}\left(K_{N}\right)} \geq 1 .
$$

Thus, for each $h \in \Gamma$, we get $c_{N+1}^{h} \leq c_{N}^{h}$, and this can be written as:

$$
w_{N+1}+f^{\prime}\left(K_{N}\right) x_{N}^{h}-x_{N+1}^{h} \leq w_{N}+f^{\prime}\left(K_{N-1}\right) x_{N-1}^{h}-x_{N}^{h} \text { for each } h \in \Gamma .
$$


Summing (A.3) over all $h \in \Gamma$, we obtain:

$$
\gamma w_{N+1}+f^{\prime}\left(K_{N}\right) \sum_{h \in \Gamma} x_{N}^{h}-\sum_{h \in \Gamma} x_{N+1}^{h} \leq \gamma w_{N}+f^{\prime}\left(K_{N-1}\right) \sum_{h \in \Gamma} x_{N-1}^{h}-\sum_{h \in \Gamma} x_{N}^{h} .
$$

By definition of $\Gamma$, we must have $\sum_{h \in \Gamma} x_{N}^{h}=K_{N}$, so that (A.4) can be written as:

$$
\gamma w_{N+1}+f^{\prime}\left(K_{N}\right) K_{N}-\sum_{h \in \Gamma} x_{N+1}^{h} \leq \gamma w_{N}+f^{\prime}\left(K_{N-1}\right) \sum_{h \in \Gamma} x_{N-1}^{h}-K_{N} .
$$

Clearly, $\sum_{h \in \Gamma} x_{N+1}^{h} \leq K_{N+1}$ and $K_{N+1}<K_{N}$. So, (A.5) yields:

$$
\begin{aligned}
\gamma w_{N+1}+f^{\prime}\left(K_{N}\right) K_{N} & \leq \gamma w_{N}+f^{\prime}\left(K_{N-1}\right) \sum_{h \in \Gamma} x_{N-1}^{h}-K_{N}+\sum_{h \in \Gamma} x_{N+1}^{h} \\
& \leq \gamma w_{N}+f^{\prime}\left(K_{N-1}\right) \sum_{h \in \Gamma} x_{N-1}^{h}-K_{N}+K_{N+1} \\
& <\gamma w_{N}+f^{\prime}\left(K_{N-1}\right) \sum_{h \in \Gamma} x_{N-1}^{h} .
\end{aligned}
$$

Then, since $\sum_{h \in \Gamma} x_{N-1}^{h} \leq K_{N-1}$, (A.6) implies that:

$$
\gamma w_{N+1}+f^{\prime}\left(K_{N}\right) K_{N}<\gamma w_{N}+f^{\prime}\left(K_{N-1}\right) K_{N-1} .
$$

We can rewrite (A.7) as:

$$
\gamma\left[w_{N+1}-w_{N}\right]<f^{\prime}\left(K_{N-1}\right) K_{N-1}-f^{\prime}\left(K_{N}\right) K_{N} .
$$

Now, noting that $\gamma \geq 1$, and

$$
w_{N+1}=\frac{f\left(K_{N}\right)-K_{N} f^{\prime}\left(K_{N}\right)}{H} \geq \frac{f\left(K_{N-1}\right)-K_{N-1} f^{\prime}\left(K_{N-1}\right)}{H}=w_{N},
$$

(since $\left.K_{N} \geq K_{N-1}\right)$, we get,

$$
\left[w_{N+1}-w_{N}\right] \leq \gamma\left[w_{N+1}-w_{N}\right]<f^{\prime}\left(K_{N-1}\right) K_{N-1}-f^{\prime}\left(K_{N}\right) K_{N}
$$

and this can be rewritten as:

$$
w_{N+1}+f^{\prime}\left(K_{N}\right) K_{N}<w_{N}+f^{\prime}\left(K_{N-1}\right) K_{N-1} .
$$

However, since $K_{N} \geq K_{N-1}$, (A.9) violates (핌). This establishes the Lemma.

Proof. of Theorem 4: We establish (i) as follows. Suppose, contrary to (i), $\left\{K_{t-1}\right\}$ is not convergent. If $\delta_{1} f^{\prime}\left(K_{t}\right)<1$, for a subsequence of periods, then by Lemma $\mathbb{W}$, there is $N \in \mathbb{N}$ such that:

$$
\begin{aligned}
& \text { (i) } K_{N-1} \leq K_{N} ; \quad K_{N+1}<K_{N}, \\
& \text { (ii) } \delta_{1} f^{\prime}\left(K_{N}\right)<1 .
\end{aligned}
$$

However, since ( $(\mathrm{MIM})$ holds, (A.10) (i) implies by Lemma $\nabla$ that $\delta_{1} f^{\prime}\left(K_{N}\right)>1$, which contradicts (A.10) (ii). Thus, there is $T \in \mathbb{N}$ such that

$$
\delta_{1} f^{\prime}\left(K_{T}\right) \geq 1 \text { for all } t \geq T .
$$


Using the Ramsey-Euler inequality for household 1, we get,

$$
\frac{u_{1}^{\prime}\left(c_{t+1}^{1}\right)}{u_{1}^{\prime}\left(c_{t}^{1}\right)} \leq \frac{1}{\delta_{1} f^{\prime}\left(K_{t}\right)} \text { for all } t \geq T .
$$

Thus, we must have,

$$
c_{t+1}^{1} \geq c_{t}^{1} \text { for all } t \geq T \text {. }
$$

This implies that $\left\{c_{t}^{1}\right\}$ must converge to some $c^{\prime}>0$, and using this in (A.12), we have

$$
\limsup _{t \rightarrow \infty} \delta_{1} f^{\prime}\left(K_{t}\right) \leq 1
$$

On the other hand, by (A.11), we have

$$
\liminf _{t \rightarrow \infty} \delta_{1} f^{\prime}\left(K_{t}\right) \geq 1
$$

Thus,

$$
\liminf _{t \rightarrow \infty} \delta_{1} f^{\prime}\left(K_{t}\right)=1=\limsup _{t \rightarrow \infty} \delta_{1} f^{\prime}\left(K_{t}\right) .
$$

But this means that $\left\{K_{t}\right\}$ is convergent, a contradiction. This establishes (i).

Using (i), we see that (ii) follows from Theorem B]. This establishes the Theorem.

\section{B Proof of Proposition 2}

Following Lemma will be useful for the proof of the Proposition $\square$.

Lemma 3. On any period three Ramsey equilibrium which is inefficient, following capital stock ownership pattern must hold.

$$
x_{T-1}^{1}>0 ; \quad x_{T}^{1}>0 ; \quad \text { and } \quad x_{T+1}^{1}=0 .
$$

Proof. As a preliminary observation, we note that:

$$
K_{T}>K^{g}
$$

For if $K_{T} \leq K^{g}$, then $K_{t} \leq K^{g}$ for all $t \geq 0$, and so $f^{\prime}\left(K_{t}\right) \geq 1$ for all $t \geq 0$. By the criterion of Cass (1972), the Ramsey Equilibrium path must then be efficient, a contradiction.

Also, since $\liminf _{t \rightarrow \infty} K_{t} \geq \underline{\mathrm{K}}$, where $\delta_{2} f^{\prime}(\underline{\mathrm{K}})=1$, and the path is periodic, we have:

$$
K_{t} \geq \underline{\mathrm{K}} \text { and } \delta_{2} f^{\prime}\left(K_{t}\right) \leq 1 \text { for all } t \geq 0 .
$$

If the conditions of the lemma do not hold, then consider the case where $x_{T}^{1}=0$, i.e., when the capital stock is at its maximum level, the patient agent does not hold any capital. In this case, $x_{T}^{2}=K_{T}>0$. Then,

$$
c_{T}^{2}=w_{T}+\left(1+r_{T}\right) x_{T-1}^{2}-x_{T}^{2}=w_{T}+\left(1+r_{T}\right) x_{T-1}^{2}-K_{T}
$$

and

$$
\begin{aligned}
c_{T+1}^{2} & =w_{T+1}+\left(1+r_{T+1}\right) x_{T}^{2}-x_{T+1}^{2}=w_{T+1}+\left(1+r_{T+1}\right) K_{T}-x_{T+1}^{2} \\
& \geq w_{T+1}+\left(1+r_{T+1}\right) K_{T}-K_{T+1} .
\end{aligned}
$$


Further, by the choice of $K_{T}=M$, we have,

$$
K_{T} \geq K_{T-1}
$$

so that:

$$
\begin{aligned}
w_{T+1} & =\left[f\left(K_{T}\right)-K_{T} f^{\prime}\left(K_{T}\right)\right] / 2 \\
& \geq\left[f\left(K_{T-1}\right)-K_{T-1} f^{\prime}\left(K_{T-1}\right)\right] / 2=w_{T}
\end{aligned}
$$

We have the (Euler E) equation:

$$
\frac{u_{2}^{\prime}\left(c_{T+1}^{2}\right)}{u_{2}^{\prime}\left(c_{T}^{2}\right)}=\frac{1}{\delta_{2} f^{\prime}\left(K_{T}\right)} .
$$

Thus, using $(\mathbb{B} .8)$ and $(\mathbb{B} .3)$ we have:

$$
c_{T+1}^{2} \leq c_{T}^{2} .
$$

So, by using (B.4), (B.5)), (B.6),$(\mathbb{B} .7)$ and (B.9) we must have:

$$
x_{T-1}^{2}>0 \text {. }
$$

By periodicity and the recurrence theorem, we must also have:

$$
x_{T+1}^{2}=0 \text { and } x_{T+1}^{1}=K_{T+1} .
$$

Since $x_{T-1}^{2}>0$, we have the (EulerE) equation:

$$
\frac{u_{2}^{\prime}\left(c_{T}^{2}\right)}{u_{2}^{\prime}\left(c_{T-1}^{2}\right)}=\frac{1}{\delta_{2} f^{\prime}\left(K_{T-1}\right)} \text {. }
$$

Using (B.3), we get:

$$
\delta_{2} f^{\prime}\left(K_{T-1}\right) \leq 1 .
$$

Thus, using (B.TU) and (B.TI) we have:

$$
c_{T}^{2} \leq c_{T-1}^{2}
$$

Combining (B.9) and (B.T2), we obtain:

$$
c_{T+1}^{2} \leq c_{T-1}^{2} .
$$

Since $x_{T-2}^{2}=x_{T+1}^{2}=0$, we have:

$$
\begin{aligned}
c_{T-1}^{2} & =w_{T-1}+\left(1+r_{T-1}\right) x_{T-2}^{2}-x_{T-1}^{2}=w_{T-1}-x_{T-1}^{2} \\
& =\left[f\left(K_{T-2}\right)-K_{T-2} f^{\prime}\left(K_{T-2}\right)\right] / 2-x_{T-1}^{2},
\end{aligned}
$$

and since $x_{T+1}^{2}=0$, we also have:

$$
\begin{aligned}
c_{T+1}^{2} & =w_{T+1}+\left(1+r_{T+1}\right) x_{T}^{2}-x_{T+1}^{2}=w_{T+1}+\left(1+r_{T+1}\right) K_{T} \\
& =\left[f\left(K_{T}\right)-K_{T} f^{\prime}\left(K_{T}\right)\right] / 2+\left(1+r_{T+1}\right) K_{T} .
\end{aligned}
$$

But, using the fact that:

$$
K_{T} \geq K_{T+1}=K_{T-2}
$$

and (B.14), (B.15), we must have:

$$
c_{T+1}^{2}>c_{T-1}^{2},
$$

which contradicts (B.T3). Thus this possibility is ruled out.

The remaining possibility is $x_{T}^{1}>0$. In this case, we break up our analysis into four sub cases. 
(a) $x_{T-1}^{1}=x_{T+1}^{1}=0$;

(b) $x_{T-1}^{1}>0$ and $x_{T+1}^{1}>0$;

(c) $x_{T-1}^{1}=0$ and $x_{T+1}^{1}>0$; and

(d) $x_{T-1}^{1}>0$ and $x_{T+1}^{1}=0$.

The first three sub cases are discussed as under.

(a) In this sub case,

$$
c_{T}^{1}=w_{T}+\left(1+r_{T}\right) x_{T-1}^{1}-x_{T}^{1}=w_{T}-x_{T}^{1}<w_{T},
$$

and

$$
\begin{aligned}
c_{T+1}^{1} & =w_{T+1}+\left(1+r_{T+1}\right) x_{T}^{1}-x_{T+1}^{1} \\
& =w_{T+1}+\left(1+r_{T+1}\right) x_{T}^{1}>w_{T+1} .
\end{aligned}
$$

Further,

$$
K_{T} \geq K_{T-1}
$$

so that:

$$
\begin{aligned}
w_{T+1} & =\left[f\left(K_{T}\right)-K_{T} f^{\prime}\left(K_{T}\right)\right] / 2 \\
& \geq\left[f\left(K_{T-1}\right)-K_{T-1} f^{\prime}\left(K_{T-1}\right)\right] / 2=w_{T} .
\end{aligned}
$$

Thus, (B.T6), (B.T7) and (B.T8) imply:

$$
c_{T+1}^{1}>c_{T}^{1} .
$$

Since $x_{T}^{1}>0$, we have the (Euler $\left.E\right)$ equation:

$$
\frac{u_{1}^{\prime}\left(c_{T+1}^{1}\right)}{u_{1}^{\prime}\left(c_{T}^{1}\right)}=\frac{1}{\delta_{1} f^{\prime}\left(K_{T}\right)} .
$$

Using (B.2), we get:

$$
\delta_{1} f^{\prime}\left(K_{T}\right)<1
$$

Combining (B.2U) and (B.2T), we have:

$$
u_{1}^{\prime}\left(c_{T+1}^{1}\right)>u_{1}^{\prime}\left(c_{T}^{1}\right)
$$

which contradicts (B.19). Thus sub case (a) cannot arise.

(b) In this sub case $x_{t}^{1}>0$ for all $t \geq 0$. Then, we have the (EulerE) equation:

$$
\frac{\delta_{1} u_{1}^{\prime}\left(c_{t+1}^{1}\right)}{u_{1}^{\prime}\left(c_{t}^{1}\right)}=\frac{1}{f^{\prime}\left(K_{t}\right)} \text { for all } t \geq 1
$$

Using the price sequence $\left\{p_{t}\right\}$ defined by $(\mathbb{\mathbb { U }})$, we obtain from (B.22) , for all $\tau \geq 1$,

$$
\frac{p_{\tau+1}}{p_{0}}=\frac{\delta_{1}^{\tau+1} u_{1}^{\prime}\left(c_{\tau+1}^{1}\right)}{u_{1}^{\prime}\left(c_{1}^{1}\right) f^{\prime}\left(K_{0}\right)} .
$$

Since $c_{\tau+1}^{1} \geq \eta$ for all $\tau \geq 1$, the right-hand side of (B.23) converges to zero as $\tau \rightarrow \infty$. Thus $p_{\tau+1} \rightarrow 0$ as $\tau \rightarrow \infty$, by (B.23); condition ( $\mathbb{K} T \mathbf{C})$ is satisfied and the Ramsey Equilibrium is efficient by Theorem 1 . This contradiction shows that sub case (b) cannot arise. 
(c) We analyze this sub case by further subdividing into two parts (I) $x_{T}^{2}>0$; (II) $x_{T}^{2}=0$.

(I) Observe that agent 2 holds positive capital stock in periods $T-1$ and $T$. Then by the recurrence theorem, we must have $x_{T+1}^{2}=0$. Using the (Euler $\left.\mathrm{E}\right)$ equations for household 2 , in periods $T$ and $T-1$, we get:

$$
\frac{u_{2}^{\prime}\left(c_{T+1}^{2}\right)}{u_{2}^{\prime}\left(c_{T}^{2}\right)}=\frac{1}{\delta_{2} f^{\prime}\left(K_{T}\right)} \quad \text { and } \quad \frac{u_{2}^{\prime}\left(c_{T}^{2}\right)}{u_{2}^{\prime}\left(c_{T-1}^{2}\right)}=\frac{1}{\delta_{2} f^{\prime}\left(K_{T-1}\right)} .
$$

Using property (B.3), we obtain:

$$
c_{T+1}^{2} \leq c_{T}^{2} \leq c_{T-1}^{2}
$$

However,

$$
\begin{aligned}
c_{T+1}^{2} & =w_{T+1}+\left(1+r_{T+1}\right) x_{T}^{2}-x_{T+1}^{2}=w_{T+1}+\left(1+r_{T+1}\right) x_{T}^{2} \\
& >\left[f\left(K_{T}\right)-K_{T} f^{\prime}\left(K_{T}\right)\right] / 2,
\end{aligned}
$$

and:

$$
\begin{aligned}
c_{T-1}^{2} & =w_{T-1}+\left(1+r_{T-1}\right) x_{T-2}^{2}-x_{T-1}^{2}=w_{T-1}-x_{T-1}^{2} \\
& <\left[f\left(K_{T-2}\right)-K_{T-2} f^{\prime}\left(K_{T-2}\right)\right] / 2,
\end{aligned}
$$

since $x_{T-2}^{2}=x_{T+1}^{1}=0$. Then (B.25) and (B.26) contradict (B.24), since $K_{T} \geq K_{T-2}=K_{T+1}$.

(II) In this case, we use the (EulerE) equation for household 1 to get:

$$
\frac{u_{1}^{\prime}\left(c_{T+1}^{1}\right)}{u_{1}^{\prime}\left(c_{T}^{1}\right)}=\frac{1}{\delta_{1} f^{\prime}\left(K_{T}\right)} .
$$

By (B.2), we have $\delta_{1} f^{\prime}\left(K_{T}\right)<1$, and so (B.27) yields:

$$
c_{T+1}^{1} \leq c_{T}^{1} .
$$

However,

$$
\begin{aligned}
c_{T+1}^{1} & =w_{T+1}+\left(1+r_{T+1}\right) x_{T}^{1}-x_{T+1}^{1}>w_{T+1}-x_{T+1}^{1} \\
& \geq\left[f\left(K_{T}\right)-K_{T} f^{\prime}\left(K_{T}\right)\right] / 2-K_{T+1},
\end{aligned}
$$

and:

$$
\begin{aligned}
c_{T}^{1} & =w_{T}+\left(1+r_{T}\right) x_{T-1}^{1}-x_{T}^{1}=w_{T}-x_{T}^{1} \\
& =\left[f\left(K_{T-1}\right)-K_{T-1} f^{\prime}\left(K_{T-1}\right)\right] / 2-K_{T},
\end{aligned}
$$

since $x_{T}^{2}=0$ and so $x_{T}^{1}=K_{T}$. Clearly (B.29) and (B.30) contradict (B.28) since $K_{T} \geq K_{T+1}$ and $K_{T} \geq K_{T-1}$. Thus, we can conclude that sub case (c) cannot arise.

The discussion of all the cases above, leaves us with the sub case (d). Hence for a period three Ramsey equilibrium to be inefficient, it is necessary that the conditions of the Lemma hold. 
Proof. of Proposition 2: Using Lemma B, we know that (B.1) holds for any period three inefficient Ramsey equilibrium. We employ the two (EulerE) equations for household 1 (using $x_{T}^{1}>0$ and $x_{T-1}^{1}>0$ ) to get:

$$
\frac{u_{1}^{\prime}\left(c_{T+1}^{1}\right)}{u_{1}^{\prime}\left(c_{T}^{1}\right)}=\frac{1}{\delta_{1} f^{\prime}\left(K_{T}\right)} \quad \text { and } \quad \frac{u_{1}^{\prime}\left(c_{T}^{1}\right)}{u_{1}^{\prime}\left(c_{T-1}^{1}\right)}=\frac{1}{\delta_{1} f^{\prime}\left(K_{T-1}\right)}
$$

This yields:

$$
\frac{u_{1}^{\prime}\left(c_{T+1}^{1}\right)}{u_{1}^{\prime}\left(c_{T-1}^{1}\right)}=\frac{u_{1}^{\prime}\left(c_{T+1}^{1}\right)}{u_{1}^{\prime}\left(c_{T}^{1}\right)} \frac{u_{1}^{\prime}\left(c_{T}^{1}\right)}{u_{1}^{\prime}\left(c_{T-1}^{1}\right)}=\frac{1}{\left(\delta_{1}\right)^{2} f^{\prime}\left(K_{T}\right) f^{\prime}\left(K_{T-1}\right)} .
$$

Note that since $x_{T+1}^{1} \equiv x_{T-2}^{1}=0$, we have:

$$
\begin{aligned}
c_{T+1}^{1} & =w_{T+1}+\left(1+r_{T+1}\right) x_{T}^{1}-x_{T+1}^{1}=w_{T+1}+\left(1+r_{T+1}\right) x_{T}^{1} \\
& >\left[f\left(K_{T}\right)-K_{T} f^{\prime}\left(K_{T}\right)\right] / 2,
\end{aligned}
$$

and:

$$
\begin{aligned}
c_{T-1}^{1} & =w_{T-1}+\left(1+r_{T-1}\right) x_{T-2}^{1}-x_{T-1}^{1}=w_{T-1}-x_{T-1}^{1} \\
& <\left[f\left(K_{T-2}\right)-K_{T-2} f^{\prime}\left(K_{T-2}\right)\right] / 2 .
\end{aligned}
$$

Using (B.32) and (B.33)), we infer:

$$
c_{T+1}^{1}>c_{T-1}^{1},
$$

since $K_{T} \geq K_{T+1} \equiv K_{T-2}$. Using (B.34) and (B.3T), we obtain:

$$
\left(\delta_{1}\right)^{2} f^{\prime}\left(K_{T}\right) f^{\prime}\left(K_{T-1}\right)>1 .
$$

Using (B.2) and (B.35), we get:

$$
f^{\prime}\left(K_{T-1}\right)>\frac{1}{\left(\delta_{1}\right)^{2}}>1
$$

Thus, we must have:

$$
K_{T-1}<K^{g}
$$

Using (B.35) again, we have:

$$
\left(\delta_{1}\right)^{2} f^{\prime}\left(K_{T+1}\right) f^{\prime}\left(K_{T}\right) f^{\prime}\left(K_{T-1}\right)>f^{\prime}\left(K_{T+1}\right),
$$

and by the Cass criterion (CC) of inefficiency, we must have:

$$
1>f^{\prime}\left(K_{T+1}\right) f^{\prime}\left(K_{T}\right) f^{\prime}\left(K_{T-1}\right) .
$$

Using (B.38) in (B.37) yields:

$$
1>\left(\delta_{1}\right)^{2}>f^{\prime}\left(K_{T+1}\right)
$$

and so:

$$
K_{T+1}>K^{g} \text {. }
$$

We now use (B.36) and (B.40) to examine the behavior of household 2. In particular, we claim that:

$$
x_{T}^{2}=0 .
$$

For, if (B.4T) is violated, then we have $x_{T}^{2}>0$ and also $x_{T+1}^{2}=K_{T+1}>0$ (since $x_{T+1}^{1}=0$ by Lemma B), so that by the recurrence theorem we have:

$$
x_{T-1}^{2}=0,
$$


and the (EulerE) equations for household 2 yield:

$$
\frac{u_{2}^{\prime}\left(c_{T+1}^{2}\right)}{u_{2}^{\prime}\left(c_{T}^{2}\right)}=\frac{1}{\delta_{2} f^{\prime}\left(K_{T}\right)} \geq 1 \quad \text { and } \quad \frac{u_{2}^{\prime}\left(c_{T+2}^{2}\right)}{u_{2}^{\prime}\left(c_{T+1}^{2}\right)}=\frac{1}{\delta_{2} f^{\prime}\left(K_{T+1}\right)} \geq 1,
$$

using observation (B.3). Thus, we obtain:

$$
c_{T-1}^{2} \equiv c_{T+2}^{2} \leq c_{T+1}^{2} \leq c_{T}^{2} .
$$

However, we have:

$$
\begin{aligned}
c_{T}^{2} & =w_{T}+\left(1+r_{T}\right) x_{T-1}^{2}-x_{T}^{2}=w_{T}-x_{T}^{2} \\
& <\left[f\left(K_{T-1}\right)-K_{T-1} f^{\prime}\left(K_{T-1}\right)\right] / 2,
\end{aligned}
$$

and:

$$
\begin{aligned}
c_{T-1}^{2} & =w_{T-1}+\left(1+r_{T-1}\right) x_{T-2}^{2}-x_{T-1}^{2}=w_{T-1}+\left(1+r_{T-1}\right) x_{T-2}^{2} \\
& >\left[f\left(K_{T-2}\right)-K_{T-2} f^{\prime}\left(K_{T-2}\right)\right] / 2,
\end{aligned}
$$

using (B.42). Since $K_{T-2} \equiv K_{T+1}>K_{T-1}$ by $(\mathrm{B} .36)$ and (B.401), we must have:

$$
c_{T-1}^{2}>\left[f\left(K_{T-2}\right)-K_{T-2} f^{\prime}\left(K_{T-2}\right)\right] / 2>\left[f\left(K_{T-1}\right)-K_{T-1} f^{\prime}\left(K_{T-1}\right)\right] / 2>c_{T}^{2},
$$

and this contradicts (B.43). This establishes our claim (B.4I), and therefore part (b) of the Proposition.

Part (a) of the Proposition will be established, given (B.36) and (B.40) if we can prove that:

$$
K_{T}>K_{T+1} .
$$

If (B.44) were violated then $K_{T}=K_{T+1}$, and further since $x_{T+1}^{2}=K_{T+1}>0$, the (EulerE) equation for household 2 yields:

$$
\frac{u_{2}^{\prime}\left(c_{T+2}^{2}\right)}{u_{2}^{\prime}\left(c_{T+1}^{2}\right)}=\frac{1}{\delta_{2} f^{\prime}\left(K_{T+1}\right)} \geq 1
$$

using observation (B.3). Thus, we must have:

$$
c_{T-1}^{2} \equiv c_{T+2}^{2} \leq c_{T+1}^{2} .
$$

However, we have:

$$
\begin{aligned}
c_{T+1}^{2} & =w_{T+1}+\left(1+r_{T+1}\right) x_{T}^{2}-x_{T+1}^{2}=w_{T+1}-x_{T+1}^{2} \\
& =\left[f\left(K_{T}\right)-K_{T} f^{\prime}\left(K_{T}\right)\right] / 2-K_{T+1},
\end{aligned}
$$

and:

$$
\begin{aligned}
c_{T+2}^{2} & =w_{T+2}+\left(1+r_{T+2}\right) x_{T+1}^{2}-x_{T+2}^{2}>w_{T+2}-x_{T+2}^{2} \\
& \geq\left[f\left(K_{T+1}\right)-K_{T+1} f^{\prime}\left(K_{T+1}\right)\right] / 2-K_{T-1} .
\end{aligned}
$$

So, using $K_{T}=K_{T+1}$ and $K_{T+1}>K_{T-1}$, we get $c_{T+2}^{2}>c_{T+1}^{2}$, contradicting (B.46). This establishes (B.44) and therefore part (a) of the Proposition. 
We note that, having established (a), (B.45) can be strengthened to read:

$$
\frac{u_{2}^{\prime}\left(c_{T+2}^{2}\right)}{u_{2}^{\prime}\left(c_{T+1}^{2}\right)}=\frac{1}{\delta_{2} f^{\prime}\left(K_{T+1}\right)}>1,
$$

so that we have a strengthened version of (B.46):

$$
c_{T-1}^{2} \equiv c_{T+2}^{2}<c_{T+1}^{2} .
$$

To establish part (c) of the Proposition, we use (B.39) and (B.44) to infer that:

$$
1>\left(\delta_{1}\right)^{2}>f^{\prime}\left(K_{T+1}\right)>f^{\prime}\left(K_{T}\right) .
$$

Then we use (B.35) and (B.48) to obtain:

$$
\left(\delta_{1}\right)^{4} f^{\prime}\left(K_{T-1}\right)>\left(\delta_{1}\right)^{2} f^{\prime}\left(K_{T}\right) f^{\prime}\left(K_{T-1}\right)>1 .
$$

By observation (B.3.3) we also have:

$$
1 \geq \delta_{2} f^{\prime}\left(K_{T-1}\right)
$$

Combining (B.49) and (B.50), we obtain:

$$
\delta_{2}<\left(\delta_{1}\right)^{4}
$$

which establishes part (c) of the Proposition.

To prove part (d), we note that since $x_{T}^{1}=K_{T}>K^{g}$, we can employ the (Euler E) equation for household 1 to get:

$$
\frac{u_{1}^{\prime}\left(c_{T+1}^{1}\right)}{u_{1}^{\prime}\left(c_{T}^{1}\right)}=\frac{1}{\delta_{1} f^{\prime}\left(K_{T}\right)}>1 \text {. }
$$

This yields:

$$
c_{T+1}^{1}<c_{T}^{1}
$$

Thus, combining (B.34) and (B.5]), we obtain:

$$
c_{T-1}^{1}<c_{T+1}^{1}<c_{T}^{1}
$$

which establishes (d).

To establish part (e), we make an observation about the aggregate consumption in periods $T$ and $T+1$,

$$
\begin{aligned}
c_{T}^{1}+c_{T}^{2} & =c_{T}=f\left(K_{T-1}\right)-K_{T}<f\left(K_{T}\right)-K_{T} \\
& <f\left(K_{T}\right)-K_{T+1}=c_{T+1}=c_{T+1}^{1}+c_{T+1}^{2} .
\end{aligned}
$$

Using (B.5T) and (B.52), we get:

$$
c_{T+1}^{2}>c_{T}^{2}
$$

Combining (B.47) and (B.53), we obtain:

$$
c_{T+1}^{2}>\max \left\{c_{T}^{2}, c_{T-1}^{2}\right\} .
$$

which establishes (e). 
Finally, to establish (f), we proceed as follows. Note that since $x_{T+1}^{1}=0$, we have:

$$
\begin{aligned}
c_{T+1}^{1} & =w_{T+1}+\left(1+r_{T+1}\right) x_{T}^{1}-x_{T+1}^{1} \\
& =w_{T+1}+\left(1+r_{T+1}\right) K_{T},
\end{aligned}
$$

and:

$$
\begin{aligned}
c_{T}^{1} & =w_{T}+\left(1+r_{T}\right) x_{T-1}^{1}-x_{T}^{1} \\
& \leq w_{T}+\left(1+r_{T}\right) K_{T-1}-K_{T} .
\end{aligned}
$$

Using (B.5T), (B.54) and (B.55), we infer:

$$
\left(1+r_{T}\right) K_{T-1}>K_{T}+\left(1+r_{T+1}\right) K_{T}+\left(w_{T+1}-w_{T}\right) .
$$

Since $x_{T}^{2}=0$ while $x_{T+1}^{2}=K_{T+1}$, we have:

$$
c_{T+1}^{2}=w_{T+1}+\left(1+r_{T+1}\right) x_{T}^{2}-x_{T+1}^{2}=w_{T+1}-K_{T+1},
$$

and:

$$
\begin{aligned}
c_{T}^{2} & =w_{T}+\left(1+r_{T}\right) x_{T-1}^{2}-x_{T}^{2} \\
& =w_{T}+\left(1+r_{T}\right) x_{T-1}^{2} \geq w_{T} .
\end{aligned}
$$

Using (B.53), (B.57) and (B.58), we obtain:

$$
K_{T+1}<w_{T+1}-w_{T} .
$$

Combining (B.56) and (B.59), we get:

$$
\left(1+r_{T}\right) K_{T-1}>K_{T}+\left(1+r_{T+1}\right) K_{T}+K_{T+1} .
$$

Since $K_{T-1}<K_{T+1}$, while $K_{T}>K_{T+1}$, the inequality in (BB.60) yields:

$$
\left(1+r_{T}\right) K_{T+1}>K_{T+1}+\left(1+r_{T+1}\right) K_{T+1}+K_{T+1} .
$$

Thus, we obtain:

$$
f^{\prime}\left(K_{T-1}\right)=\left(1+r_{T}\right)>1+\left(1+r_{T+1}\right)+1=2+f^{\prime}\left(K_{T}\right) .
$$

Using (B.35) in (B.62), we obtain finally:

$$
f^{\prime}\left(K_{T-1}\right)>\left[2+\frac{1}{f^{\prime}\left(K_{T-1}\right)}\right] .
$$

Define $g(z)=z^{2}-2 z-1$ for all $z \in \mathbb{R}$. Then, $g(z)>0$ and $z>0$ implies $z>\sqrt{2}+1$. Thus, (B.63) implies that:

$$
f^{\prime}\left(K_{T-1}\right)>\sqrt{2}+1
$$

Since $\delta_{2} f^{\prime}\left(K_{T-1}\right) \leq 1$, we must have:

$$
\delta_{2}<\frac{1}{\sqrt{2}+1}=\sqrt{2}-1 \approx 0.414
$$




\section{Example of Production Function satisfying MIM}

Consider the class of CES production functions given by

$$
G(K, L)=A\left[\alpha K^{-\rho}+(1-\alpha) L^{-\rho}\right]^{-\frac{1}{\rho}} \text { for all }(K, L) \gg 0,
$$

where $A>0, \alpha \in(0,1)$ and $\rho>0$. In this case the (constant) elasticity of substitution is given by:

$$
\sigma=\frac{1}{1+\rho}<1
$$

The Cobb-Douglas production function is obtained as a limiting case by letting $\rho \rightarrow 0$, and so $\sigma \rightarrow 1$.

Since each household supplies one unit of labor, we can define the function $g(K)$ as:

$$
g(K)=G(K, H)=A\left[\alpha K^{-\rho}+(1-\alpha) H^{-\rho}\right]^{-\frac{1}{\rho}} \text { for all } K>0,
$$

so that we have, for all $K>0$,

$$
g(K)^{-\rho}=A^{-\rho} \alpha K^{-\rho}+A^{-\rho}(1-\alpha) H^{-\rho}=a K^{-\rho}+b,
$$

where $a \equiv A^{-\rho} \alpha$ and $b \equiv A^{-\rho}(1-\alpha) H^{-\rho}$.

Note that as $K \rightarrow 0$, we have $g(K) \rightarrow 0$. So, we can define $g(0)=0$ and preserve continuity of $g$ on $\mathbb{R}_{+}$. The difficulty is that $g^{\prime}(K)$ is bounded as $K \rightarrow 0$. While one can ensure that the marginal product is very high for $K$ near 0 (by taking $A$ large), one does not know whether the existence of a Ramsey Equilibrium can be ensured from every positive initial capital stock, and initial ownership pattern of the capital stock.

So, we consider instead of (CES) the approximate CES production function, given by:

$$
f(K)= \begin{cases}\theta g(K)+(1-\theta) s(K) & \text { for all } K>0 \\ 0 & \text { for } K=0,\end{cases}
$$

where $\theta \in(0,1)$, and $s(K)$ is a (reduced-form) function,

$$
s(K)=B K^{\beta} \text { for all } K>0,
$$

obtained from the Cobb-Douglas production function, with $B>0$ and $\beta \in(0,1)$. Then, $f$ satisfies all the maintained assumptions of our basic framework. For $\theta \approx 1, f$ is an approximate CES function. Note that we have:

(i) $f^{\prime}(K)=\theta g^{\prime}(K)+(1-\theta) s^{\prime}(K)$ for all $K>0$

(ii) $f^{\prime \prime}(K)=\theta g^{\prime \prime}(K)+(1-\theta) s^{\prime \prime}(K)$ for all $K>0$.

Thus, we have:

$$
\begin{aligned}
\frac{K\left[-f^{\prime \prime}(K)\right]}{f^{\prime}(K)} & =\frac{K \theta\left[-g^{\prime \prime}(K)\right]+K(1-\theta)\left[-s^{\prime \prime}(K)\right]}{\theta g^{\prime}(K)+(1-\theta) s^{\prime}(K)} \\
& \leq \frac{K \theta\left[-g^{\prime \prime}(K)\right]}{\theta g^{\prime}(K)}+\frac{K(1-\theta)\left[-s^{\prime \prime}(K)\right]}{(1-\theta) s^{\prime}(K)} \\
& =\frac{K\left[-g^{\prime \prime}(K)\right]}{g^{\prime}(K)}+\frac{K\left[-s^{\prime \prime}(K)\right]}{s^{\prime}(K)}
\end{aligned}
$$


Differentiating (C.4) with respect to $K$, and simplifying, we obtain:

$$
g^{\prime}(K)=a\left[\frac{g(K)}{K}\right]^{\rho+1} \text { for all } K>0 .
$$

Differentiating (C.6) with respect to $K$, we obtain,

$$
g^{\prime \prime}(K)=a(\rho+1)\left[\frac{g(K)}{K}\right]^{\rho} \frac{K g^{\prime}(K)-g(K)}{K^{2}} .
$$

Using (‥6) and (C.7), we can simplify to obtain,

$$
e_{g}(K) \equiv\left[\frac{-K g^{\prime \prime}(K)}{g^{\prime}(K)}\right]=(\rho+1)\left[1-\frac{K g^{\prime}(K)}{g(K)}\right]<\rho+1
$$

since $\left[1-\frac{K g^{\prime}(K)}{g(K)}\right] \in(0,1)$. Also,

$$
e_{s}(K) \equiv\left[\frac{-K s^{\prime \prime}(K)}{s^{\prime}(K)}\right]=1-\beta
$$

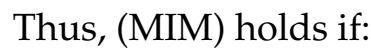

$$
[(\rho+1)+(1-\beta)]\left[1-\frac{1}{H}\right]<1,
$$

which can be rewritten as:

$$
0<\rho+1<\left[\frac{H}{H-1}\right]-(1-\beta) .
$$

Since the constant elasticity of substitution of $\mathrm{g}$ is $\sigma_{g}=[1 /(1+\rho)]$, (MUM) holds if:

$$
\frac{1}{\sigma_{g}}<\frac{H}{H-1}-(1-\beta)
$$

By choosing $\beta$ sufficiently close to 1 in the function $s(K)$, (C.8) can be made to hold if:

$$
\frac{1}{\sigma_{g}}<\frac{H}{H-1} \quad \text { or } \quad \sigma_{g}>1-\frac{1}{H}
$$

This agrees with the formula derived earlier in Section 4.2 .

\section{Proof of Inefficiency}

Without loss of generality, consider the case where $k_{0}=\frac{174}{175}$. The equilibrium capital stock and aggregate consumption sequences in the example in Section 5.2 are,

$$
\left\{k_{t}, C_{t+1}\right\}=\left\{\begin{array}{l}
\left\{\frac{174}{175}, c+132\right\}, \text { for } t=0,3,6, \cdots \\
\left\{42, c+177+\frac{13}{36}-\frac{1}{39}\right\}, \text { for } t=1,4,7, \cdots \\
\left\{\frac{40}{39}, c+174+\frac{1}{13 \cdot 36}+\frac{1}{175}\right\}, \text { for } t=2,5,8, \cdots
\end{array}\right.
$$


We show that the capital stock sequence $\left\{k_{t}^{\prime}\right\}$ (described below) is feasible from $k_{0}$ and dominates $\left\{k_{t}\right\}$ as it provides higher aggregate consumption in period 1 and same aggregate consumption in all the remaining periods. We take $\varepsilon=\frac{1}{175}$. The dominating capital stock sequence is

$$
k_{t}^{\prime}=\left\{\begin{array}{l}
\frac{174}{175}, \text { for } t=0 \\
42-\left(\frac{175}{432}\right)^{n} \cdot(\varepsilon)>41, \text { for } t=3 n+1 \\
\frac{40}{39}-\left(\frac{175}{432}\right)^{n} \cdot\left(\frac{\varepsilon}{36}\right)>1, \text { for } t=3 n+2 \\
\frac{174}{175}-\left(\frac{175}{432}\right)^{n} \cdot\left(\frac{\varepsilon}{432}\right)>0, \text { for } t=3 n+3
\end{array}\right.
$$

where $n=0,1, \cdots$. Using the capital stock sequence given in (D.2), we can compute the aggregate output sequence as under

$$
y_{t+1}^{\prime}=f\left(k_{t}^{\prime}\right)=\left\{\begin{array}{l}
c+174, \text { for } t=0 \\
c+178+\frac{13}{36}-\left(\frac{175}{432}\right)^{n} \cdot\left(\frac{\varepsilon}{36}\right), \text { for } t=3 n+1, \\
c+175+\frac{1}{13 \cdot 36}-\left(\frac{175}{432}\right)^{n} \cdot\left(\frac{\varepsilon}{432}\right), \text { for } t=3 n+2, \\
c+174-\left(\frac{175}{432}\right)^{n+1} \cdot(\varepsilon), \text { for } t=3 n+3,
\end{array}\right.
$$

where $n=0,1, \cdots$. The corresponding aggregate consumption sequence is obtained from (D.2) and (D.3) as under

$$
C_{t+1}^{\prime}=y_{t+1}^{\prime}-k_{t+1}^{\prime}=f\left(k_{t}^{\prime}\right)-k_{t+1}^{\prime}=\left\{\begin{array}{l}
c+132+\varepsilon, \text { for } t=0, \\
c+177+\frac{13}{36}-\frac{1}{39}, \text { for } t=3 n+1, \\
c+174+\frac{1}{13 \cdot 36}+\frac{1}{175}, \text { for } t=3 n+2, \\
c+132, \text { for } t=3 n+3,
\end{array}\right.
$$

where $n=0,1, \cdots$. The sequences described above have been constructed as under:

(a) Take $C_{1}^{\prime}=C_{1}+\varepsilon$ and $C_{t}^{\prime}=C_{t} \forall t>1$. Then $k_{1}^{\prime}=k_{1}-\varepsilon=42-\frac{1}{175}>41$ and therefore $f\left(k_{1}^{\prime}\right)=f\left(k_{1}\right)-\frac{\varepsilon}{36}=$ $C_{2}+k_{2}-\left(\frac{\varepsilon}{36}\right)$.

(b) $k_{2}^{\prime}=k_{2}-\left(\frac{\varepsilon}{36}\right)=\frac{40}{39}-\frac{1}{175} \cdot \frac{1}{36}=1+\frac{1}{39}-\frac{1}{175} \cdot \frac{1}{36}>1$. Also $f\left(k_{2}^{\prime}\right)=f\left(k_{2}\right)-\left(\frac{\varepsilon}{36}\right) \cdot \frac{3}{36}=f\left(k_{2}\right)-\left(\frac{\varepsilon}{432}\right)=$ $C_{3}+k_{3}-\left(\frac{\varepsilon}{432}\right)$.

(c) $k_{3}^{\prime}=k_{3}-\left(\frac{\varepsilon}{432}\right)=k_{0}-\left(\frac{\varepsilon}{432}\right)=\frac{174}{175}-\frac{1}{175} \cdot \frac{1}{432}>0$. Further, $f\left(k_{3}^{\prime}\right)=f\left(k_{3}\right)-\left(\frac{\varepsilon}{432}\right) \cdot 175=f\left(k_{0}\right)-\left(\frac{175}{432}\right) \cdot \varepsilon=$ $C_{4}+k_{4}-\left(\frac{175}{432}\right) \cdot \varepsilon=C_{1}+k_{1}-\left(\frac{175}{432}\right) \cdot \varepsilon>f\left(k_{0}\right)-\varepsilon$.

(d) $k_{4}^{\prime}=k_{1}-\left(\frac{175}{432}\right) \cdot \varepsilon>k_{1}-\varepsilon=k_{1}^{\prime}>41$. Then $f\left(k_{4}^{\prime}\right)=f\left(k_{1}\right)-\frac{\left(\frac{175}{432}\right) \cdot \varepsilon}{36}=C_{5}+k_{5}-\left(\frac{175}{432}\right) \cdot\left(\frac{\varepsilon}{36}\right)$.

(e) $k_{5}^{\prime}=k_{5}-\left(\frac{175}{432}\right) \cdot \frac{\varepsilon}{36}>k_{2}-\frac{\varepsilon}{36}=k_{2}^{\prime}>1$. Then $f\left(k_{5}^{\prime}\right)=f\left(k_{5}\right)-\left(\frac{175}{432}\right) \cdot\left(\frac{\varepsilon}{36}\right) \cdot \frac{3}{36}=C_{6}+k_{6}-\left(\frac{175}{432}\right) \cdot\left(\frac{\varepsilon}{432}\right)$.

(f) $k_{6}^{\prime}=k_{6}-\left(\frac{175}{432}\right) \cdot\left(\frac{\varepsilon}{432}\right)=k_{3}-\left(\frac{175}{432}\right) \cdot\left(\frac{\varepsilon}{432}\right)>k_{3}-\frac{\varepsilon}{432}=k_{3}^{\prime}$.

Following the same logic we can construct the entire sequence. Comparing (ID.T) and (D.4), we get $C_{1}^{\prime}=C_{1}+\varepsilon$ and $C_{t}^{\prime}=C_{t}$ for all $t>1$ and therefore $\left\{k_{t}\right\}$ is not efficient. In case, $k_{0} \neq \frac{174}{175}$, we initiate the construction of dominating sequence from $t=2$ for $k_{0}=42$ and $t=1$ for $k_{0}=\frac{40}{39}$. 


\section{References}

R. A. Becker. On the Long-run Steady-state In A Simple Dynamic-model of Equilibrium With Heterogeneous Households. Quarterly Journal of Economics, 95(2):375-382, 1980.

R. A. Becker. Equilibrium Dynamics with Many Agents. In Rose-Anne Dana, C. Le Van, T. Mitra, and K. Nishimura, editors, Handbook of Optimal Growth 1. Springer-Verlag, 2006.

R. A. Becker and C. Foias. A Characterization of Ramsey Equilibrium. Journal of Economic Theory, 41:173184, 1987.

R. A. Becker and C. Foias. Convergent Ramsey Equilibria. Libertas Mathematica, 10:41-52, 1990.

R. A. Becker and T. Mitra. Efficient Ramsey Equilibria. Macroeconomic Dynamics, 16(Supplement S1):18-32, April 2012.

R. A. Becker, J. H. Boyd, and C. Foias. The Existence of Ramsey Equilibrium. Econometrica, 59(2):441-460, March 1991.

R. A. Becker, S. Bosi, C. Le Van, and T. Seegmullar. On existence, efficiency and bubbles of Ramsey equilibrium with borrowing constraints. CAEPR Working Paper, (001), 2012.

D. Cass. Capital Overaccumulation In Aggregative, Neoclassical Model of Economic Growth - Complete Characterization. Journal of Economic Theory, 4(2):200-223, 1972.

E. Malinvaud. Capital Accumulation and Efficient Allocation of Resources. Econometrica, 21(2):233-268, April 1953.

G. Sorger. On the Structure of Ramsey Equilibrium: Cycles, Indeterminacy, and Sunspots. Economic Theory, 4:745-764, 1994.

G. Sorger. Chaotic Ramsey Equilibrium. International Journal of Bifurcation and Chaos, 5(2):373-380, April 1995.

M. L. Stern. Personal communication. June 1, 1998. 